\title{
CRISPR/Cas9-mediated TGF $\beta$ RII disruption enhances anti-tumor efficacy of human chimeric antigen receptor T cells in vitro
}

\author{
Khadijeh Alishah ${ }^{1,2}$, Matthias Birtel², Elham Masoumi ${ }^{3}$, Leila Jafarzadeh³ ${ }^{3}$, Hamid Reza Mirzaee ${ }^{3}$, \\ Jamshid Hadjati ${ }^{3}$, Ralf-Holger Voss ${ }^{4^{*}}$, Mustafa Diken $^{2^{*}}$ and Sedighe Asad ${ }^{1 *}$
}

\begin{abstract}
Background: CAR T-cell therapy has been recently unveiled as one of the most promising cancer therapies in hematological malignancies. However, solid tumors mount a profound line of defense to escape immunosurveillance by CAR T-cells. Among them, cytokines with an inhibitory impact on the immune system such as IL-10 and TGF $\beta$ are of great importance: TGF $\beta$ is a pleiotropic cytokine, which potently suppresses the immune system and is secreted by a couple of TME resident and tumor cells.
\end{abstract}

Methods: In this study, we hypothesized that knocking out the TGF $\beta$ receptor II gene, could improve CAR T-cell functions in vitro and in vivo. Hereby, we used the CRISPR/Cas9 system, to knockout the TGF 3 RII gene in T-cells and could monitor the efficient gene knock out by genome analysis techniques. Next, Mesothelin or Claudin 6 specific CAR constructs were overexpressed via IVT-RNA electroporation or retroviral transduction and the poly-functionality of these TGF $\beta R I I K O$ CAR T-cells in terms of proliferation, cytokine secretion and cytotoxicity were assessed and compared with parental CART-cells.

Results: Our experiments demonstrated that TGF $\beta R I I$ KO CART-cells fully retained their capabilities in killing tumor antigen positive target cells and more intriguingly, could resist the anti-proliferative effect of exogenous TGF $\beta$ in vitro outperforming wild type CAR T-cells. Noteworthy, no antigen or growth factor-independent proliferation of these TGFBRII KO CAR T-cells has been recorded. TGFBRII KO CAR T-cells also resisted the suppressive effect of induced regulatory T-cells in vitro to a larger extent. Repetitive antigen stimulation demonstrated that these TGF $\beta$ RII KO CAR T-cells will experience less activation induced exhaustion in comparison to the WT counterpart.

Conclusion: The TGF $\beta$ RII KO approach may become an indispensable tool in immunotherapy of solid tumors, as it may surmount one of the key negative regulatory signaling pathways in T-cells.

\footnotetext{
*Correspondence: Ralf-Holger.Voss@unimedizin-mainz.de;

mustafa.diken@tron-mainz.de; asad@ut.ac.ir

${ }^{1}$ Department of Biotechnology, College of Science, University of Tehran,

Tehran, Iran

${ }^{2}$ TRON-Translational Oncology at the University Medical Center

of Johannes Gutenberg University gGmbH, Mainz, Germany

${ }^{4}$ Department of Research Center for Immunotherapy (FZI), University

Medical Center (UMC) of the Johannes Gutenberg University, Mainz,

Germany

Full list of author information is available at the end of the article
} otherwise in a credit line to the material. If material is not included in the article's Creative Commons licence and your intended use is not permitted by statutory regulation or exceeds the permitted use, you will need to obtain permission directly from the copyright holder. To view a copy of this licence, visit http://creativecommons.org/licenses/by/4.0/. The Creative Commons Public Domain Dedication waiver (http://creativecommons.org/publicdomain/zero/1.0/) applies to the data made available in this article, unless otherwise stated in a credit line to the data. 
Keywords: CART-cell therapy, Coinhibitory T-cell signaling, TGF $\beta$ receptor II, Genome editing, CRISPR/Cas9 knockout, IVT-RNA

\section{Background}

Adoptive cell transfer of antigen receptor modified T-cells is a promising new tool for the treatment of cancer. Besides the modification of T-cells with tumor specific T-cell receptors (TCRs), chimeric antigen receptor (CAR)-based therapies have come into focus for the treatment of several different tumor entities. CAR T-cell therapy can be regarded as one of the most promising cancer therapies in refractory hematological malignancies. The innovative idea of combining efficient, sensitive and HLA-independent antigen recognition properties of monoclonal antibodies and killing mechanism of T-cells made this system extraordinary in tracing and eradicating tumor cells [1], which has been clinically approved in patients with 'liquid' tumors such as B cell malignancies $[2,3]$. However, the other class of malignancies, solid tumors, have a multi-faceted line of strategies to escape killing by CAR T-cells, these include but are not restricted to lack of tumor specific antigens on tumor cells, imposing hurdles in trafficking and penetration of T-cells into encapsulated tumors, which on top are characterized by a hostile, immunosuppressive tumor microenvironment (TME) along with intrinsic counterregulatory mechanisms of T-cells [4].

TGF $\beta$ is one of the most critical regulators in the TME, and known to be secreted by many cancer cells such as ovarian cancer cells or by components of the immune system and stromal cells [5]. This cytokine is a pleiotropic cytokine which can modulate processes such as cell invasion, immune regulation governing suppression of host immune surveillance and regulatory T-cell differentiation, and microenvironment modification, altogether leading to tumor progression $[6,7]$. Accordingly, inhibiting TGF $\beta$ signaling has the potential to counteract the immunosuppressive milieu and boost CAR T-cell effector functions. Upon binding of TGF $\beta$ to TG $\beta$ RII, TGRRI is recruited, phosphorylated, and activated to phosphorylate the downstream mediators, Smad2 and Smad3, which further coupled with Smad4, the latter which subsequently translocate to the nucleus, and modulates transcription of several genes such as those involved in apoptosis, extracellular matrix neogenesis and immunosuppression [8]. As TGF $\beta$ RII is the initiating receptor in the TGF $\beta$ signaling cascade and isoforms are not detected yet, it was more reasonable to target it rather than TGF $\beta$ RI. It has been shown that inhibiting TGF $\beta$ signaling via overexpressing dominant-negative TGF $\beta$ RII can actively improve the antitumor functions of
T-cells and CAR T-cells in a competitive manner to WT counterpart $[9,10]$. Moreover, a clinical trial (ClinicalTrials.gov: NCT03089203) testing the safety and efficacy of the dn TGFBRII in prostate specific membrane antigen (PSMA)-specific CAR T-cells, recently reported on relapsed and refractory metastatic prostate cancer [11]. All these data suggest a potentially methodical improvement by using CRISPR/Cas9 technology to knock out endogenous TGF $\beta$ RII expression to generate engineered TGF $\beta$-resistant CAR T-cells to cope with the immunosuppressive environment within the tumor.

To address CRISPR/Cas9-driven TGF $\beta$ RII KO CAR T-cell therapy in solid tumors, this study entailed two cancer associated antigens which are not or rarely expressed on normal tissues. Claudin 6 (CLDN6) is an oncofetal tight junction protein which is frequently expressed on various human solid cancers such as ovarian cancer cells $[12,13]$. The other tumor antigen is taken from mesothelin (MSLN), a glycosylphosphatidylinositol-anchored cell surface protein that is expressed at low levels on normal mesothelial cells [14]. However, it is vastly overexpressed on a wide range of cancer tissues of epithelial origin including ovarian cancer [15].

In the current study, we hypothesized that the combination of a MSLN or CLDN6 CAR specific T-cells and a knockout of TGFßRII will unleash CAR T-cell functions even under immunosuppressive conditions applied in vitro. We could successfully eliminate expression of the TGF $\beta$ receptor II in human CD4 and CD8 T-cells using the CRISPR/Cas9 genome editing system. After introducing the CAR coding region via electroporation of in vitro transcribed RNA (IVT RNA) or retroviral transduction into the TGF $\beta$ RII KO T-cells, these engineered TGFBRII KO CAR T-cells outperformed WT CAR T-cells by means of proliferation, cytotoxicity and cytokine secretion in the presence of exogenous TGF $\beta$. Moreover, they were also able to resist the immunosuppressive effect of autologous iTregs more robustly in comparison to WT CAR T-cells. They also demonstrated improved function and less exhaustion after multiple rounds of antigen stimulation and showed no activation induced exhaustion, which eventually, ended up with better cytotoxicity after second or third antigen exposures.

\section{Material and methods}

\section{Cell lines and culture conditions}

Human cell lines, including ovarian cancer NIH-OVCAR-3 $\quad$ (RPMI $+20 \% \quad$ FBS $), \quad$ SK-OV-3 
(McCoy's 5a $+10 \%$ FBS), cervical cancer HeLa (EMEM+10\%FBS), lung cancer COLO-699 N $(\mathrm{RPMI}+10 \%$ FBS $)$, breast cancer c.l. MDA-MB-231 $(\mathrm{RPMI}+10 \%$ FBS $)$, teratocarcinoma c.l. PA1-SC12 (MEM + 10\%FBS) and HEK-293 embryonic kidney cells (DMEM + 10\%FBS) have been used in this study. MDAMB-231 and its lentiviral derivative MDA-MB-231hCLDN6 (DMEM + 10\%FBS) were also used in some experiments. The cells were routinely checked for mycoplasma contamination. All cell lines were from ATCC except COLO-699 $\mathrm{N}$ which was from ECACC.

\section{Antibodies}

CAR Mesothelin surface expression on human T-cells was assessed using primary antibody goat anti-human IgG F (ab')2 Biotin (BioRad, Hercules, CA) along with secondary conjugate Streptavidin APC (BioRad). The following antibodies were also used in FACS buffer in this study: anti-PD1-PE (Biolegends 329906), antiCCR7-Alexa-fluor 647 (BD 560921), anti-CD8-FITC (BC A07756), anti-CD8-BV421 (BD 562428), anti-HLAA2-FITC (BD 551,285), anti-CD86-PerCp-Cy5.5 (BD 561129), anti-CLDN6-Dylight 650 (IMAB027), antiidiotype-IMAB027- Alexa-fluor 647, anti-TIM3-APC (Biolegends 345011) and 7AAD (BC A07704). Mesothelin expression was detected using the PE conjugated anti mesothelin antibody (R\&D system FAB32652P). Acquisition and analysis of all samples were performed on a BD FACS CantoI/II (BD Biosciences, San Jose, California) and FlowJo software (v7.6.1).

\section{T-cell isolation and activation and human iDC generation}

PBMCs were isolated from buffy coats from healthy donors (blood transfusion center at University Medical Center (UMC) Mainz, Germany) by Ficoll ${ }^{\circledR}$-Hypaque (GE Healthcare) density gradient centrifugation. Monocytes were isolated using anti-CD14 microbeads (Miltenyi Biotec) and CD8 and CD4 cells were isolated using antiCD8 and anti-CD4 microbeads, respectively (Miltenyi Biotec) according to the manufacturer's protocol. Immature DCs (iDCs) were differentiated from $\mathrm{CD} 14^{+}$cells in RPMI 1640 GlutaMAX $^{\mathrm{TM}}, 50 \mathrm{IU} / \mathrm{mL}$ penicillin, $50 \mu \mathrm{g} /$ $\mathrm{mL}$ streptomycin, and $10 \%(\mathrm{v} / \mathrm{v})$ human $\mathrm{AB}$ serum (one lambda) (denoted huRPMI), supplemented with $1000 \mathrm{IU} /$ $\mathrm{mL}$ recombinant human (rh) GM-CSF and $1000 \mathrm{IU} / \mathrm{mL}$ rh IL-4 (Miltenyi Biotec) twice in 5 days. For T-cell activation, $2 \times 10^{6} / \mathrm{ml}$ of isolated T-cells were cultivated in 24 well tissue culture plates precoated with $2 \mu \mathrm{g} / \mathrm{ml}$ antiCD3 antibody (clone OKT3; Bioxcell) in huRPMI supplemented with $100 \mathrm{IU} / \mathrm{mL}$ IL-2 for 2 to 3 days. Cells were then harvested, washed and resuspended in huRPMI with $50 \mathrm{IU} / \mathrm{mL} \mathrm{IL}-2$ and either rested or immediately submitted to further processing steps.

\section{In vitro transcription}

The genetic construct encoding the MSLN specific chimeric antigen receptor (CAR) containing fully human anti MSLN scFv, CD8 $\alpha$ hinge/transmembrane region, and $41 \mathrm{BB}$ and $\mathrm{CD} 3 \varepsilon$ cytosolic signaling domains was generated according to the US patent 9272002 B2 and synthesized chemically. The KOZAK/coding region was subcloned into pST1 [16]-derivative MP3 553 pST1-deltaEar1-hAg-SmaI-2hBgUTR-A30L70 which is optimized for RNA in vitro transcription concerning polyA-length and composition. The codon optimized full length ORF of human mesothelin (NP_005814.2) was also subcloned into the same vector. For in vitro transcription, $10 \mu \mathrm{g}$ of plasmid preparations were digested with SapI to be linearized and then purified using QIAquick PCR purification kit (Qiagen). The linearized plasmids were subjected to T7 RNA polymerase reaction in the presence of all four ribonucleotides and D2 cap for $3 \mathrm{~h}$ at $37{ }^{\circ} \mathrm{C}$. Subsequently, template DNA was fully digested using Turbo DNase. RNA was purified using components of RNAeasy Mini kit (Qiagen) and eluted into RNase-free water. IVTRNA concentration was adjusted to $1 \mu \mathrm{g} / \mu \mathrm{l}$ and stored at $-80{ }^{\circ} \mathrm{C}$. The quality and integrity of the RNAs were confirmed using $1.5 \%$ MOPS gel. IVT-RNAs encoding the second generation CAR 8BBz CLDN6 and CLDN6 were prepared same way [13].

\section{Design and construction of CRISPRs}

Single guide RNAs (sgRNA) specific for exon 2 of TGF $\beta$ RII was designed using the CRISPR design tool provided by Synthego (https://design.synthego.com/\#/) and chemically synthesized as O-methyl-protected derivatives. Three highest-ranking gRNAs of top ten with lowest mismatch score from both strands of human TGF $\beta$ RII (Gene ID: 7048, NCBI) were selected comprising the following sequences: gRNA-3: GAAGCCACAGGAAGU CUGUG, gRNA-5: AUGAUAGUCACUGACAACAA, and gRNA-7: GCAGGAUUUCUGGUUGUCAC. The coding sequence of Cas9 was subcloned from pCAGT3-hCAS-pA (Addgene \#48625) into pST1 and IVTRNA was prepared as described before.

\section{Generation of TGF $\beta$ RII ${ }^{-}$T-cells}

T-cells were washed two times with OPTI-MEM (Invitrogen) and resuspended in serum free OPTI-MEM at a final concentration of $6-12 \times 10^{7}$ cells $/ \mathrm{mL}$. Afterwards, $100 \mu \mathrm{L}$ of cell suspension was mixed with RNAs: $10 \mu \mathrm{g}$ of Cas9 IVT-RNA and $5 \mu \mathrm{g}$ of gRNA 3/5/7 were electroporated in a 2-mm cuvette (VWR) using a PA-4000 (Harvard Apparatus BTX) at $400 \mathrm{~V}$ voltage and $2 \mathrm{~ms}$ single pulse length. Following electroporation, the cells were immediately transferred to prewarmed huRPMI culture 
media supplemented with IL2 (50 IU/mL) and incubated at $37^{\circ} \mathrm{C}$ and $5 \% \mathrm{CO}_{2}$ for 5 days.

\section{Antigen and CAR surface expression via IVT-RNA}

Wild type or TGFßRII KO T-cells were washed two times with serum free $\mathrm{X}$-vivo 15 and then resuspended in the same medium to the final concentration of $4 \times 10^{7}$ cells/ $\mathrm{mL}$. Afterwards, $250 \mu \mathrm{L}$ of the cells were mixed with $15 \mu \mathrm{g}$ of IVT-RNA CAR MSLN or $10 \mu \mathrm{g}$ of IVT-RNA CAR CLDN6 in a 4-mm cuvette (VWR) using a PA-4000 (Harvard Apparatus BTX) at $495 \mathrm{~V}$ and $9 \mathrm{~ms}$. Following electroporation, the cells were immediately transferred to prewarmed culture media and incubated at $37^{\circ} \mathrm{C}$ and $5 \%$ $\mathrm{CO}_{2}$ for $20 \mathrm{~h}$ prior to functional assays. iDCs were treated the same before electroporation and then adjusted to a cell density of $2 \times 10^{7}$ cells $/ \mathrm{mL}$ Cells were then electroporated at $300 \mathrm{~V}$ for $12 \mathrm{~ms}$ with $2 \mu \mathrm{g}$ IVT-RNA CLDN6 or $10 \mu \mathrm{g}$ MSLN. For luciferase based cytotoxicity assay the target cells were co-electroporated with $5 \mu \mathrm{g}$ of luciferase IVT-RNA.

\section{Transduction and CRISPR/Cas9 engineering of the human T-cells}

For long term cytotoxicity assay, it was necessary to stably express CAR constructs in T-cells. MACS-isolated human $\mathrm{CD}^{+}$from fresh PBMCs were pre-activated by Dynabeads $^{\mathrm{TM}}$ Human T-Activator CD3/CD28 (Gibco) in a beads to CD3+T-cell ratio of $1: 1$, in the presence of $100 \mathrm{IU} / \mathrm{ml} \mathrm{IL-2.} 48 \mathrm{~h}$ after bead-activation, cells were seeded and incubated on RetroNectin (Takarabio) pre-coated plates $(200 \mu \mathrm{l} \mathrm{of} 20 \mu \mathrm{g} / \mathrm{ml})$ saturated with CAR gamma-retroviral supernatants by centrifugation $\left(30 \mathrm{~min}, 15{ }^{\circ} \mathrm{C}, 1500 \mathrm{rpm}\right)$ to obtain an multiplicity of infection (MOI) for T-cell: viral particle ratio of 1. After extra $48 \mathrm{~h}$, pre-activation Dynabeads ${ }^{\mathrm{TM}}$ Human T-Activator CD3/CD28 were removed from culture and cells were electroporated for Cas9 mRNA and TGF $\beta$ RIIspecific gRNAs as described before. Non-transduced T-cells served as controls. Heterologous CAR expression on transduced human T-cells was assessed via flow cytometry.

Platinum-E cells were used for preparation of GALV pseudotyped viral particles. Cells were transfected with TransIT-LT1 (Mirus) according to the manufacturer's instructions. Retroviral supernatants were collected 48 and $72 \mathrm{~h}$ after transfection and titers were evaluated using Jurkat cells.

\section{Gene disruption efficiency assay using T7 endonuclease I assay, sequencing and TIDE assay}

Five days after electroporation with gRNA and Cas9 mRNA, genomic DNA was extracted from the cells using QIAmp DNA mini kit (Qiagen) according to the manufacturer's instructions. The genomic regions flanking the sgRNA target site in the TGF $\beta$ RII gene were PCR amplified with the following primers: TGF $\beta$ RII forward: 5'AGAAAGTGGACCTTATGACAACCA, and TGFßRII-reverse: 5'-AGGAGGTGTCGGTTAAATGAC TAC using Q5 high fidelity DNA polymerase (NEB). The PCR products were either purified and Sanger sequenced with TGFßRII-sequencing primer: 5'-TCTGATGTG AAGGAATTATTTTGCCT and then subjected to TIDE analysis using the online tool http://tide.nki.nl (Analyses were performed using a reference sequence from a Cas9 mock-electroporated sample) or subjected to T7EI Nuclease (NEB) assay as previously described. Briefly, the PCR products were first heated up to $90{ }^{\circ} \mathrm{C}$ to be denatured and then the temperature gradually decreased to $10{ }^{\circ} \mathrm{C}$ to reanneal the product. The mixtures were then subjected to T7E1 digestion for 15 min which recognizes mismatches, and finally analysed on a $2 \%$ agarose gel.

Luciferase, spheroid and impedance-based cell lysis assays For luciferase-based cytotoxicity assay, WT CAR T-cells or TGFBRII KO CAR T-cells were cocultured in triplicates with the Ag and luciferase expressing target cells at the indicated E:T ratio $20 \mathrm{~h}$ after electroporation in white Nunclon Delta surface 96 well plates. Three hours after setting up the coculture, $50 \mu \mathrm{l}$ of the substrate solution, $1 \mathrm{mg} / \mathrm{ml}$ Luciferin (BD, moonlight D-luciferin) and $50 \mathrm{mM}$ HEPES, was added to each well. Triton-X100 $(0.25 \%$ f.c.) was added for full lysis control. The bioluminescence emission was recorded using Tecan Infinite 200 reader at indicated time points and the cytotoxicity was calculated as follows:

$$
\operatorname{specificlysis}(\%)=\left(1-\frac{\left(L_{\text {sample }}-L_{\max }\right)}{\left(L_{\min }-L_{\max }\right)}\right) * 100
$$

$L_{\text {sample: }}$ Luminescence mean by sample lysis

$L_{\text {max }}$ : Luminescence mean by maximal lysis

$L_{\text {min }}$ : Luminescence mean by spontaneous lysis

To mimic the 3D nature of tumors, spheroid-based cytotoxicity assay was performed using the Incucyte live cell imaging system. For generating the spheroids, tumor cell lines were electroporated with eGFP mRNA and seeded in spheroid plates (Corning \#7007) for $24 \mathrm{~h}$. After $24 \mathrm{~h}$, the generations of spheroids and fluorescence emissions were confirmed using the Incucyte, and WT CAR T-cells or TGF $\beta$ RII KO CAR T-cells were added to the corresponding wells, and reduction of the fluorescence intensity was monitored over time. The data were analyzed using Incucyte software and the background was subtracted using the Top Hat algorithm. 
An impedance-based tumor lysis cell culture system (xCELLigence, ACEA Biosciences) was used to assess the long-term T-cell cytotoxicity in real-time. By means of an electrode-bottomed plate, the device measures the electrode impedance of adherent target cells which corresponds to cell viability, and reports it using a unitless parameter called Cell Index (CI). Cell lysis leads to detachment of target cells decreasing CI over time. Target cells were seeded on 96-well electrode-bottomed microtiter plates (E-Plate ${ }^{\circledR} 96$ ) at $2 \times 10^{4}$ cells/100 $\mu \mathrm{L} /$ well. After 20 to $24 \mathrm{~h}$, right before when CI starts to plateau, the effector cells were added at indicated E:T ratios and the CI was recorded every $15 \mathrm{~min}$. To correct for diverging growth curve properties on a 96-well plate ('edge effects'), CIs of any time point were first normalized to the CI (NCI) shortly before effector cells were added to every well and averaged over replicates. Specific lysis was calculated via the following formula taken from RTCA software:

$$
\text { specificlysis }(\%)=\left(1-\frac{\left(N C I_{\text {sample }}-N C I_{\max }\right)}{\left(N C I_{\min }-N C I_{\max }\right)}\right) * 100
$$

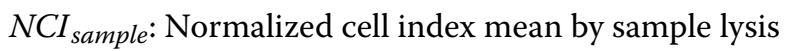
$N C I_{\text {max }}$ : Normalized cell index mean by maximal lysis $N C I_{\text {min }}$ : Normalized cell index mean by spontaneous lysis

\section{Repetitive antigen stimulation assay}

Target cells were seeded on Xcelligence plates $\left(2 \times 10^{4}\right.$ cells/100 $\mu \mathrm{L} /$ well), and after 20 to $24 \mathrm{~h}$, WT or TGF $\beta$ RII KO CD8 + T-cells, which were retrovirally transduced to express a CLDN6 specific CAR were added at an E:T ratio of 5:1 in the presence or absence of TGF $\beta$. Cytotoxicity was monitored for $48 \mathrm{~h}$ in real time. Subsequently, CAR T-cells were collected from wells, washed, counted again and added to a new Xcelligence plate containing previously seeded target cells the same way as before. The amount of cell lysis was monitored again for $48 \mathrm{~h}$, and the same procedure repeated one more time. The concentration of TGF- $\beta 1$ was maintained at $5 \mathrm{ng} / \mathrm{mL}$ in the treatment group.

\section{Proliferation}

Either WT CAR T-cells or TGFßRII KO CAR T-cells were labeled with $0.8 \mu \mathrm{M}$ carboxyfluorescein diacetate succinimidyl ester (CFSE, Invitrogen) or $10 \mu \mathrm{M}$ eBioscience $^{\text {TM }}$ Cell Proliferation Dye eFluor ${ }^{\mathrm{TM}} 450$ (CPD450) and cocultured with Ag mRNA-electroporated iDCs at an E:T ratio of 5:1 in round-bottom 96 well plates with different doses of TGF- $\beta 1$ (carrier-free; R\&D Systems). An aliquot of culture supernatants was harvested after $24 \mathrm{~h}$ for cytokine analysis.
After 5 days of coculture T-cells were stained with antiCD8 or anti-CD4 antibody and the reduction of CFSEstaining as readout for cell divisions measured using the high through put sampler (HTS) implemented on a FACS canto II device.

\section{Cytokine enzyme-linked immunosorbent assay (ELISA)}

WT CAR T-cells or TGFBRII KO CAR T-cells were cocultured with Ag mRNA-electroporated iDCs or cancer cell lines at different E:T ratios in round-bottom 96 well plates in a final volume of $200 \mu \mathrm{l}$. After $24 \mathrm{~h}, 100 \mu \mathrm{l}$ of supernatant was collected and frozen down to $-80^{\circ} \mathrm{C}$ for analysis later on, or 1:2-1:10 dilutions in assay diluent were assayed immediately by incubating for $3 \mathrm{~h}$ at $37^{\circ} \mathrm{C}$ on high protein binding 96-well plates precoated with a cytokine-specific capture antibody. After repetitive washing immobilized cytokines (IFN- $\gamma$ ) were detected with a biotinylated detection antibody/streptavidin-HRP-conjugate after addition of the substrate NBT. Color development was photometrically quantified on TECAN Sunrise ELISA reader system and quantified by calculation of $\mu \mathrm{g} / \mathrm{ml}$ via a cytokine standard developed in parallel. The supernatants were assayed for producing human IL-2 and IFN- $\gamma$ using human ELISA kit (Invitrogen), while Granzyme B (GrB), TNF- $\alpha$ and GM-CSF were quantified by the DuoSet ELISA Development Kit (R\&D Systems).

\section{iTreg generation in vitro suppression assay}

$\mathrm{CD} 4^{+} \mathrm{T}$-cells were positively selected from fresh PBMCs using CD4 microbeads (Miltenyi-Biotec) according to the manufacturer's protocol and rested for $3 \mathrm{~h}$. Cells were then plated in 24 well plates precoated with $5 \mu \mathrm{g} / \mathrm{ml}$ antiCD3 antibody (clone OKT3; Bioxcell) at $2 \times 10^{6}$ cells/well in serum-free X-Vivo 15 medium (Lonza) supplemented with $1 \mu \mathrm{g} / \mathrm{ml}$ soluble anti-CD28 antibody (Biolegend, ultra-LEAF grade) and $100 \mathrm{IU} / \mathrm{ml}$ IL-2. Cells stimulated with only these reagents served as control. For iTreg generation, $5 \mathrm{ng} / \mathrm{ml}$ of TGF- $\beta 1$ (carrier-free; R\&D Systems), $10 \mathrm{nM}$ of all trans retinoic acid (ATRA) (SigmaAldrich) and $100 \mathrm{ng} / \mathrm{ml}$ of rapamycin (Calbiochem EMD Millipore) were added to the culture media. Cells were incubated for 6 days at $37{ }^{\circ} \mathrm{C} / 5 \% \mathrm{CO}_{2}$ in an incubator. Thereafter, $\mathrm{CD} 4+\mathrm{T}$-cells being committed to differentiate into induced Tregs (iTregs) were washed and rested for two to three days in X-Vivo 15 medium with $50 \mathrm{U} /$ $\mathrm{ml}$ IL-2. For setting up the suppression assay, iTregs were washed again and resuspended in fresh medium without any IL-2. The responder (Tresp) cells were either WT CAR T-cells or TGF $\beta$ RII KO CAR T-cells. Tresp were labeled with $10 \mu \mathrm{M}$ CPD-450 as described before and the coculture set up as followed: In each well of roundbottom 96 plate, constant number of Tresp cells $\left(5 \times 10^{4}\right)$ and Ag expressing iDCs as target cells $\left(1 \times 10^{4}\right)$ were 
coseeded and additionally, cocultivated with suppressive iTregs or activated CD4+T-cells as negative control at different ratios (2:1,1:1, 0.5:1 and 0.25:1). Cells were cultured for 3 to 4 days and suppression in proliferation was analysed by flow cytometry.

\section{Results and discussion}

\section{MSLN and CLDN6 specific CAR T-cells recognize and kill} cognate antigen expressing tumor cell lines

In this study, we focused on CAR T-cells specific for the tumor antigens mesothelin and claudin 6 (Fig. 1A), which are highly expressed on tumor cells but rarely detected on normal cells. We either used antigen overexpressing cell lines, HeLa (Fig. 1B i) and OVCAR-3 (Fig. 1B ii) for MSLN-specific antigenicity, PA-1 SC12 (Fig. 1B vi) and OVCAR-3 (Fig. 1B vii) for CLDN6-reactivity or exogenously overexpressed the antigen on the cell surface of iDCs (MSLN and CLDN6) (Fig. 1B iii, ix) or (MDAMB-231) (Fig. 1B viii) via IVT-RNA electroporation or virus transduction. The MSLN-negative cancer cell lines SK-OV-3 (Fig. 1B iv) and Colo-699 N (Fig. 1B v) are also used in some experiments.

We activated $\mathrm{CD} 4+/ \mathrm{CD} 8+\mathrm{T}$-cells and transfected them with MSLN $(15 \mu \mathrm{g})$ and CLDN6 $(10 \mu \mathrm{g})$ CAR encoding IVT RNAs. At this high dose, we could monitor around 50\% CAR expression for both antigen specificities (Fig. 1C i, D i).

To confirm that the CAR MSLN T-cells are functional in vitro we performed multiple assessments. In the first step, IFN- $\gamma$ secretion was examined against different-cell lines: CAR MSLN T-cells secreted high level of IFN- $\gamma$ towards MSLN expressing cell lines, up to $4000 \mathrm{pg} / \mathrm{mL}$ in case of OVCAR-3 and $1500 \mathrm{pg} / \mathrm{mL}$ in case of HeLa cell line as target cell (Fig. $1 \mathrm{C}$ ii). There was no significant secretion of this cytokine against the negative control cell lines SK-OV-3 and COLO-699 N. Furthermore, cell cytotoxicity was evaluated by means of a 3D culture spheroid lysis assay (Fig. 1C iii). Solid phase spheroid cells reflect the in vivo situation in some aspects such as actively dividing tumor cells at its boundaries with optimal nutrients provision, and at its core tumor cells becoming apoptotic or necrotic [17]. However, it does not embrace immunosuppressive and angiogenetic effects in TME. Our data confirmed that the CAR MSLN T-cells successfully kill the tumor spheroids even at a low E:T ratio of 1:1, which could achieve almost $100 \%$ killing in $24 \mathrm{~h}$ as opposed to mock T-cells. Decrease of fluorescence in negative controls reflects the degradation of GFP encoding mRNA over time. Conclusively, these data proved cytokine secretion and cytotoxic function of CAR MSLN T-cells. We also performed this experiment for the MSLN-negative cell line SK-OV-3 and data showed that the CAR MSLN T cells did not exert any cytotoxicity on this cell line at a high E: $\mathrm{T}$ ratio of 30:1. The recorded slow decrease in green intensity in both mock and CAR MSLN T cells is probably due to the half-life of the electroporated mRNA (Additional file 1: Fig. S1).

To assess CAR CLDN6 functionality, CAR CLDN6 T-cells were cocultured with IVT-RNA electroporated iDCs expressing CLDN6 heterologously at increasing doses for an E:T ratio of 5:1 to quantify secreted IFN- $\gamma$ in an ELISA. The amount of detected cytokine ranged between $1000 \mathrm{pg} / \mathrm{ml}$ for $2 \mu \mathrm{g}$ electroporated CLDN6 and $100 \mathrm{pg} / \mathrm{ml}$ for $0.02 \mu \mathrm{g}$ electroporated CLDN6 (Fig. 1D ii), and hence, decreased dose-dependently.

For the impedance based cytotoxicity assay, we electroporated the SK-OV-3 cell line with $2 \mu \mathrm{g}$ CLDN6 RNA and seeded them on xcelligence plates. After $24 \mathrm{~h}$, the CAR CLDN6 or the mock T-cells were added at an E:T ratio of 5:1 and the impedance changes were recorded over time. Successful killing of CLDN6 ${ }^{+}$SK-OV-3 cells by CAR CLDN6 effector T-cells (70\%) was confirmed, while no relevant cytotoxicity was observed for mock T-cells (Fig. 1D iii).

We also evaluated the proliferation of CAR CLDN6 T-cells applying a CFSE dilution-based assay in a dose

(See figure on next page.)

Fig. 1 MSLN and CLDN6 are highly expressed on tumor cell lines and CAR CLDN6 or MSLN recognize and kill them efficiently. A A 2nd Gen. CAR CLDN6 or MSLN construct based on chimerisation to the hinge, transmembrane, and cytosolic region of CD8a, the cytosolic region of 4-1BB and CD3c for costimulatory and stimulatory signaling, respectively. B MSLN expression on i) Hela and ii) OVCAR-3 cell line, iii) exogenous MSLN expression on iDCs after electroporation of $10 \mu \mathrm{g}$ MSLN IVT-RNA, and non-expressing tumor cell line iv) SK-OV-3 and v) Colo-699 N. Endogenous CLDN6 expression on vi) PA-1 and vii) OVCAR-3 cell surface viii) exogenous CLDN6 expression on MDA-MB-231 after transduction with CLDN6 encoding virus particles, and ix) CLDN6 expression on iDCs after electroporation of $2 \mu \mathrm{g}$ CLDN6 IVT-RNA, respectively. C: i) CAR MSLN expression on human CD8 T cells one day after electroporation with $10 \mu \mathrm{g}$ CAR MSLN IVT-RNA, ii) IFN- $\gamma$ secretion assay proved that MSLN-specific CAR recognizes MSLN positive cells (HeLa and OVCAR-3), while they do not react with antigen negative cell lines (SK-OV-3 and COLO-699 N), iii) Spheroid killing assay demonstrated that CAR MSLN T-cells recognize and kill HeLa tumor spheroids at also a very low E:T-ratio. D: i) CAR CLDN6 expression on human CD8 T cells one day after electroporation with $10 \mu \mathrm{g}$ CAR CLDN6 IVT-RNA, ii) IFN- $\gamma$ secretion assay proved that CAR CLDN6 can specifically recognize CLDN6 electroporated iDCs in a dose dependent manner while they do not react with antigen negative cells, iii) Xcelligence based killing assay showed that CAR CLDN6 T-cells recognize and kill exogenously CLDN6 expressing SK-OV-3 cell lines, while mock T-cells remained inactive. vi) CFSE based proliferation assay showed that CAR CLDN6 T cells divided strongly up to a frequency of $80 \%$, not only in the presence of a high dose of heterologously expressed CLDN6 in iDCs $(2 \mu \mathrm{g})$, but also at a dose of as low as $0.02 \mathrm{ug}$ CLDN6. P values were determined by one-way Anova using multiple comparison test. ${ }^{*} P<0.05 ;{ }^{* *} P<0.01 ;{ }^{* * *} \mathrm{P}<0.001 ;{ }^{* * *} \mathrm{P}<0.0001$. In all experiments, mean \pm SD of three technical replicates are given and experiments, involving $T$ cells, are repeated for at least three donors 

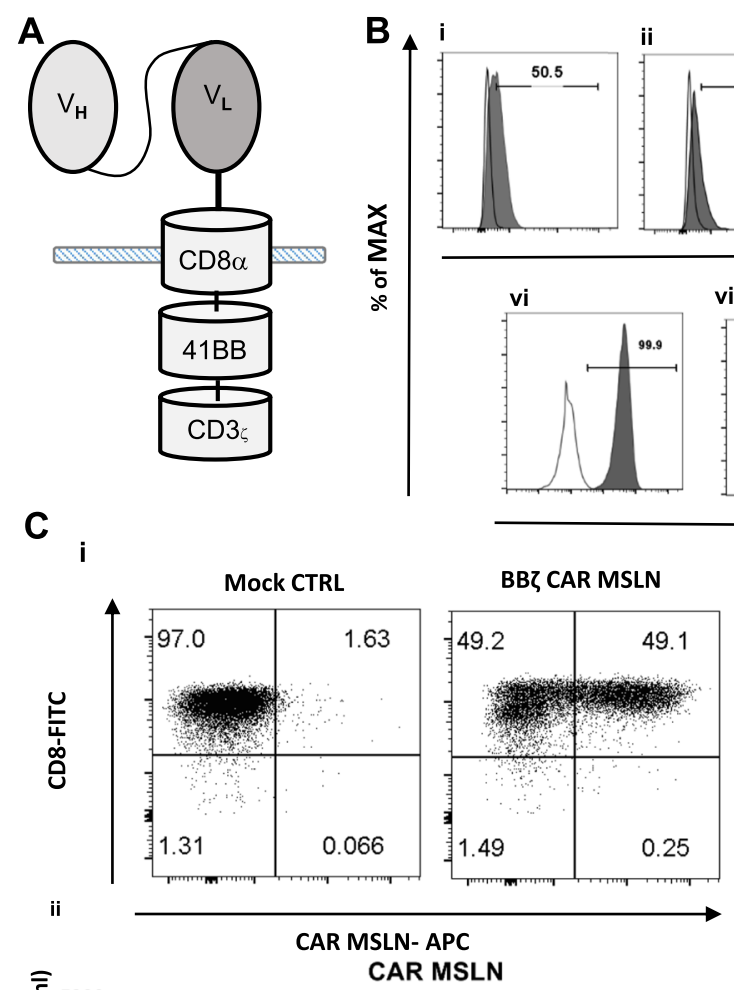

C i

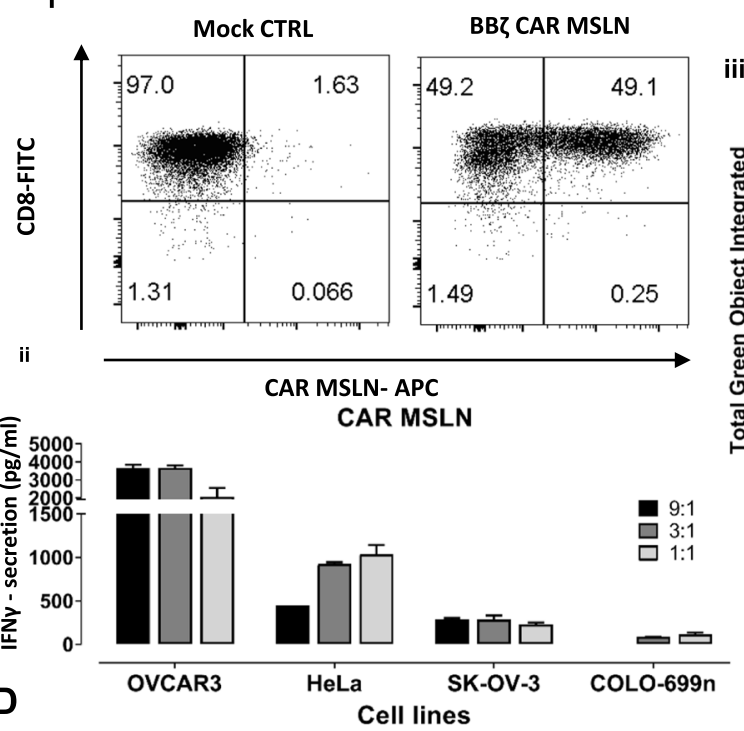

CLDN6-dyelight 650
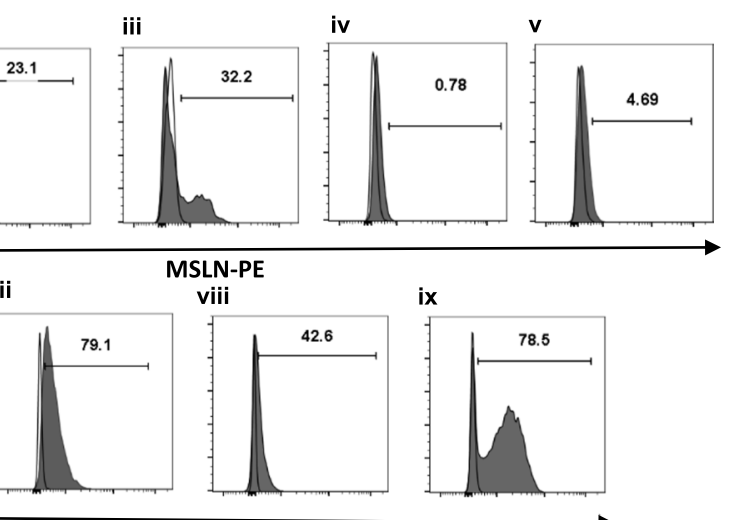

iii
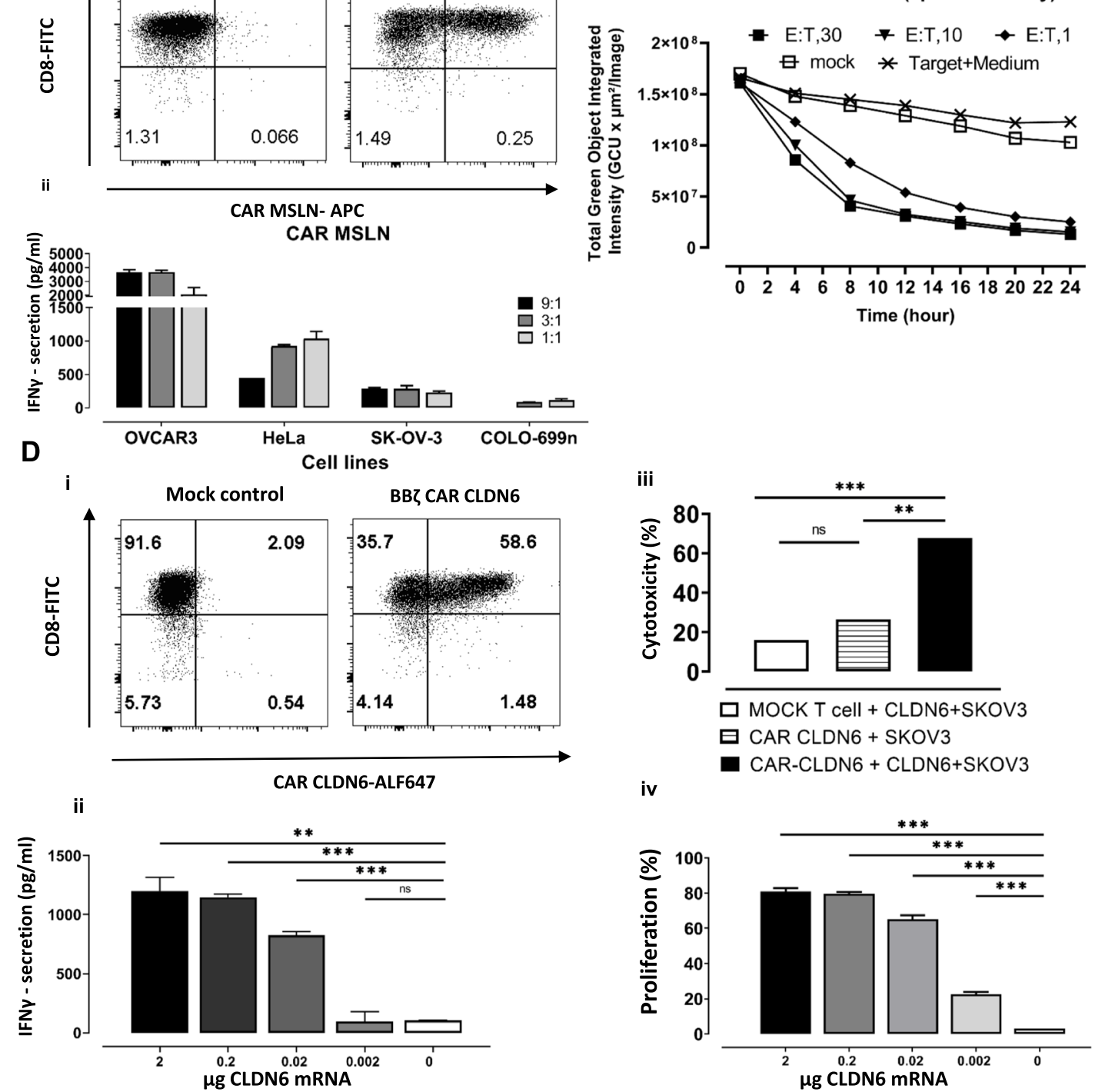

iv

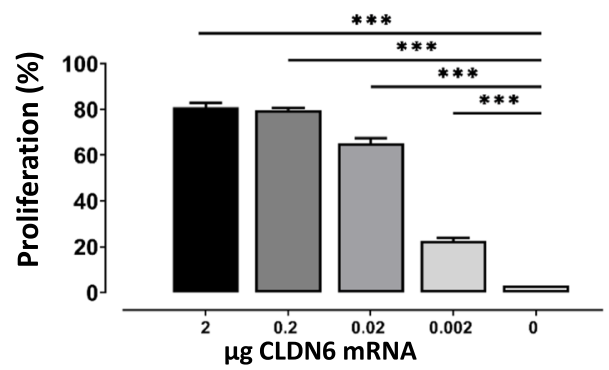

Fig. 1 (See legend on previous page.) 
dependent manner. These CAR T-cells divided strongly up to a frequency of $80 \%$, not only in the presence of a high dose of heterologously expressed CLDN6 in iDCs (2 $\mu \mathrm{g})$, but also at a dose of as low as $0.02 \mu \mathrm{g}$ CLDN6 (70\%; Fig. 1D iv). Notably, no proliferation was detectable in the presence of mock-electroporated iDCs. In conclusion, our data confirmed that both CARs specific for MSLN and CLDN6 elicited superior effector functions against antigen expressing tumor cell lines or iDCs.

\section{Exogenous TGF $\beta$ impairs CAR T-cell proliferation in vitro}

Due to the fact that TGF $\beta$ is one of the key regulators of the immune system in the tumor microenvironment, which vastly suppresses CAR T-cell function [9], we hypothesized that one of the hurdles in solid tumor CAR T-cell therapy arise from high levels of TGF $\beta$ in TME. To test this hypothesis, we performed a series of in vitro tests to find out if exogenous TGF $\beta$ can exert a suppressive effect on our CAR T-cells specific for 2 different tumor antigens. IVT electroporated iDCs (CLDN6/ MSLN) were cocultured with CAR CLDN6 or CAR MSLN T-cells at increasing doses of TGF $\beta$. A broad range of exogenous TGF $\beta$ added $(5-20 \mathrm{ng} / \mathrm{ml})$ could significantly suppress CAR T-cell functions in terms of cytokine secretion (Fig. 2A) and proliferation (Fig. 2B) which is consistent with previous reports. Secretion of IFN- $\gamma$, the most prevailing immunostimulatory T-cells' cytokine, is very susceptible to even the lowest dose of TGF $\beta$ added, dropping to less than $40 \%$ of the IFN- $\gamma$ secretion in absence of TGF $\beta$. In line to that, proliferation of both MSLN and CLDN6 specific CAR T-cells was reduced to less than of $50 \%$ of their native proliferation (i.e. absence of TGF $\beta$ ) in the presence of even very low dose of TGF $\beta$ ( $5 \mathrm{ng} / \mathrm{ml}$ ). Noteworthy, the suppressive effect of TGF $\beta$ did not only last for short-term incubation times $(<24 \mathrm{~h})$ as it is demonstrated here for an IFN- $\gamma$ ELISA, but was also obvious for long-term proliferation assays (5-6 days). In conclusion, these data demonstrated that TGF $\beta$ is a potent inhibitor of CAR T-cells, regardless of their antigen specificity.

We should mention that there is not any robust data on precise level of active TGF $\beta$ at tumor site. Data are mostly focused on blood which was in the range of 0.5$25 \mathrm{ng} / \mathrm{mL}$ in human plasma [18] and it is stated that the concentration of TGF $\beta$ is much higher in cancer patients in comparison to a normal control [19]. Reasonably, the concentration of active TGF $\beta$ should be higher in tumor in comparison to plasma because the tumor cells secrete TGF $\beta$ by themselves, which can be activated by a matrix metalloprotease. As others, such as Hou et al. [20], also used $5 \mathrm{ng} / \mathrm{ml}$ TGF $\beta$ in their studies, we decided to use this concentration as starting concentration. Since we are primarily interested in testing the potency of our TGF $\beta$ RII KO CAR T-cells, we primarily checked higher levels of TGF $\beta$ to make sure that our knocked-out groups can also resist higher levels of TGF $\beta$ which we speculate to prevail in TME.

\section{Deletion of TGF $\beta$ RII via CRISPR/Cas9 system}

We prompted us to assess whether genomic disruption of TGFßRII in CAR T-cells will counteract the
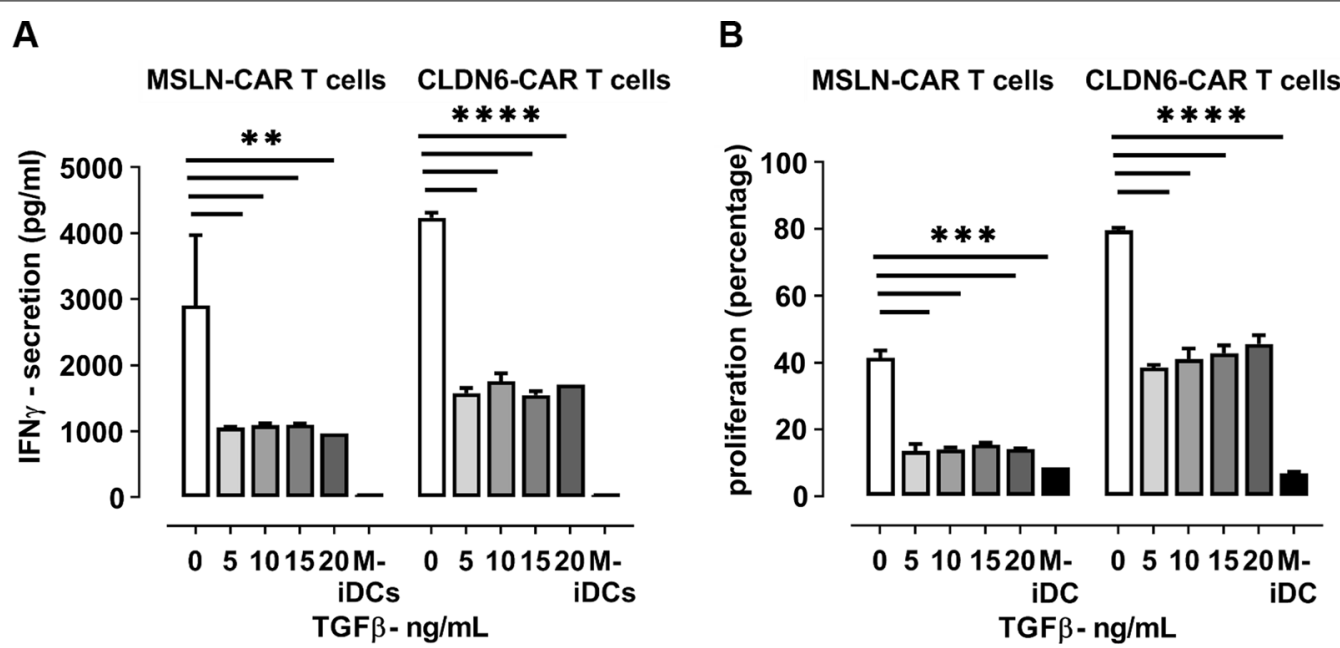

Fig. 2 Exogenous TGF $\beta$ impairs CAR T-cell cytokine secretion and proliferation in vitro. A TGF $\beta$ is able to inhibit IFN- $\gamma$ secretion of MSLN- or CLDN6-specific CAR 4-1BBל T-cells towards antigen-pulsed iDCs in a broad dose range $(5-20 \mathrm{ng} / \mathrm{mL})$ and on a short time line (20 h). B TGF $\beta$ is also able to inhibit proliferation of MSLN- or CLDN6-specific CAR 4-1BBC T-cells towards antigen-pulsed iDCs in a broad dose range (5-20 ng/mL) and on a long time line (5 days). P values were determined by two-way Anova using multiple comparison test. ${ }^{*} \mathrm{P}<0.05$; ${ }^{* *} \mathrm{P}<0.01$; ${ }^{* * *} \mathrm{P}<0.001$; ${ }_{* * * *} \mathrm{P}<0.0001$. In all experiments, mean $\pm \mathrm{SD}$ of three technical replicates are given and experiments, involving $T$ cells, are repeated for at least three donors 
aforementioned functional impairment of CAR T-cells in the presence of exogenous TGF $\beta$. To achieve this purpose, we designed a 2-step protocol comprising CRISPR/ Cas9 based gene knock out of the TGF $\beta$ RII locus and subsequent CAR IVT-RNA electroporation into those genomically edited primary human T-cells (Fig. 3A). The RNA-guided Cas 9 nuclease from the microbial CRISPR adaptive immune system is an efficient genome editing tool which consists of nuclease Cas9 and a single-guide RNA (sgRNA) targeting a 20-bp region of the genomic region of interest [21]. We used the Synthego online tool to design sgRNAs and selected three gRNAs from the top ranked suggested sgRNAs on both strands with at least 50 nucleotides distances (Fig. 3B). The Synthego online tool uses the Doench et al. [22] scoring algorithm to select efficient sgRNAs and also ranks the sgRNAs based on the numbers of genomic off targets. Number of potential off target sites for zero, one and two mismatches was zero for gRNAs 3/5, while in the case of gRNA7, four off targets emerged with two mismatches. However, we cannot entirely rule out that off-target edits might occur which need to be assessed by next generation sequencing before entering the clinical setting. To combine the knock out procedure and CAR expression, briefly, OKT3 activated T-cells were electroporated with Cas9 mRNA alone (Cas9 control), or Cas9 and chemically synthesized O-methyl protected sgRNA targeting TGF $\beta$ RII exon 2. Five days later, TGF $\beta$ RII ablation was checked using genomic analysis techniques by means of a T7 endonuclease I assay and Sanger sequencing. Cells were subsequently electroporated with saturating amounts of IVT mRNA encoding the anti-MSLN or anti-CLDN6 CAR (Fig. 3A).

To determine the knock out efficiency, genomic DNA was extracted from the cells (Cas9 only and Cas9 with gRNAs 3, 5 or 7) and was submitted to PCR amplification using PCR primers flanking the sgRNA targeting region. An aliquot of the PCR products was subjected to T7 endonuclease I restriction and then run on an agarose gel (Fig. 3c).

T7 endonuclease I recognizes and cleaves mis-matched DNA, which could lead to extra bands on the gel in case of indel formations. The PCR product from control cells and the three gRNAs treated cells were submitted to digestion by T7E1 enzyme. While there were no extra bands in the control, all gRNA treated groups exhibited extra bands which indicates indel formations (Fig. 3C). As outlined in Fig. 3B, each gRNA targets nearby but different genomic sequences of the TGF $\beta$ RII gene and hence, taking into account using identical PCR primers, the restriction pattern of T7E1 ended up with variably sized restriction products for each gRNA visible on the gel. The PCR products were also delivered for Sanger sequencing and the data were analyzed for indel frequencies applying a decomposition technique. Base ambiguities commence after base 4 of gRNA7 (5'-GTGA-A/C...), which is consistent with the postulated genomic cut site of Cas9 (Fig. 3D, Additional file 2: Fig. S2). Again, results confirmed indel formations in all gRNA treated groups (Fig. 3D/E). Although gRNA3 was prone to form less indels in comparison to the two other gRNAs (Fig. 3E), we did not exclude it from our further experiments so as to check if even a lower level of genomic TGFßRII knock out might also have a measurable effect on CAR T-cell functions. In summary, these data exhibited the successful generation of insertions/deletions (INDELs) in the TGF $\beta$ RII gene locus. We were able to demonstrate gene ablation to similar degrees for the 3 scrutinized gRNAs in both, CD8 + and CD4+ cells, respectively (Fig. 3E).

\section{TGF $\beta$ RII disruption in CAR T-cells enhances their in vitro effector functions}

To determine the effect of TGF $\beta$ RII deficiency on CAR T-cell function, we assessed TGF $\beta$ RII KO CAR MSLN and CAR CLDN6 T-cells in different assays in vitro. Due to limited $\mathrm{KO}$ efficacy, these experiments were done on bulk populations that contained both edited and nonedited cells. As an essential prerequisite for comparison of KO CAR T-cells with WT CAR T-cells, gene ablation of TGF $\beta R I I$ must not interfere with IVT-RNA-mediated CAR expression in T-cells. Indeed, we observed very similar frequencies of CAR expression on T-cells (Fig. 4A): 50\% CAR expression could be observed for both, CAR-MSLN electroporated T-cells and TGFBRII KO CAR-MSLN T-cells. Similar to that, we also found up to 70\% CAR expression in electroporated T-cells for CAR CLDN6 irrespective of the genomic editing step. Additionally, we analyzed proliferation of WT or KO

\footnotetext{
(See figure on next page.)

Fig. 3 The TGF $\beta$ RII locus is successfully targeted via CRISPR/Cas9 system. A Schematic illustration of genomically knocking out TGF $\beta$ RII taking advantage of synthetic gRNAs targeting the TGFBRII locus and IVT-RNA of the nuclease Cas9, followed by IVT-RNA based CAR expression in human T-cells. B Graphic representation of the sequence and genomic location of three different gRNAs targeting exon 2 of TGF $\beta$ RII and 20 bases in length, arrows indicate the polarity of the gRNAs. CT7 endonuclease 1 assay showing extra bands for gRNA treated T-cell groups in contrast to the control group, confirming indel formation in the gRNA treated group. D Histogram sequencing results for wild type and gRNA7 treated groups, elicit a heterologous sequence 4 bases inside the gRNA target target sequence upstream of complementary 5'-NGG PAM-sequence, which is in line with indel formation. E Bar graph of TIDE analysis illustrates that all three different gRNAs can lead to successful TGF $\beta$ RIl knockout in both human $\mathrm{CD} 4+$ and $\mathrm{CD} 8+\mathrm{T}$-cells. In all experiments, mean \pm SD of three technical replicates are given and experiments, involving $T$ cells, are repeated for at least three donors
} 
A Schematic representation of TGFBRII knocked out CAR T cells work flow

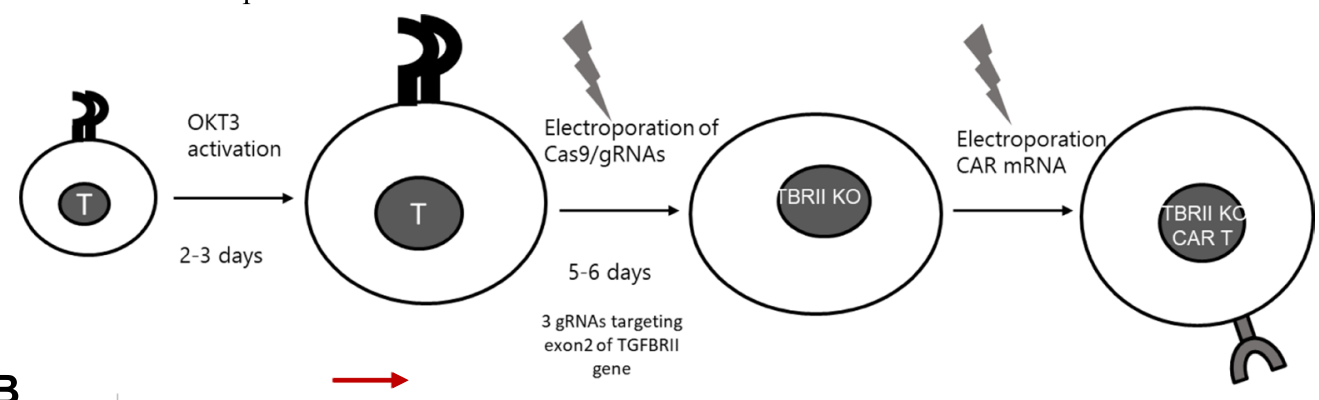

B

5. ttaataacgacatgatagtcactgacaacaa cggtgcagtcaagtttccacaactgtgta

3' aat tat gctgtactatcagtgactgttgttgccacgtcagt tcaaaggtgt tgacacat gRNA

aatttgtgatgtgagattttccacctgtgacaaccagaatcctgcatgagcaactgca

t taaacactacactctaaagg tggacactgttggtctttaggacgtactcgttgacgt

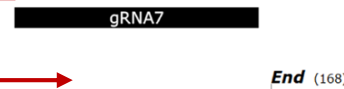

gcatcacctccatctgtgagaagccacaggaagtctgtgtggktgtat ${ }^{\prime}{ }_{16}$ cgtagtggaggtagacactcttcggtgtccttcagacacaccgacata $5^{\prime}{ }^{168}$

C

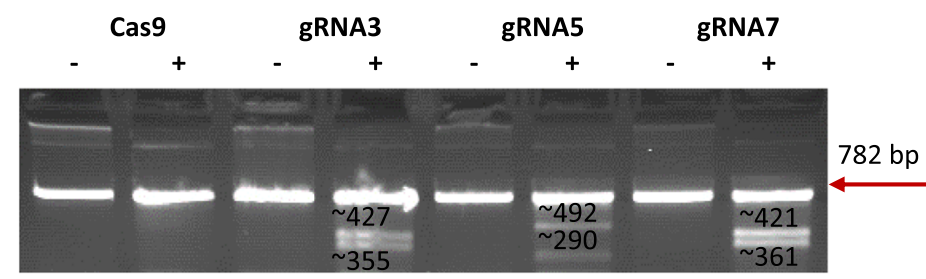

-/+ T7E1 digestion

D

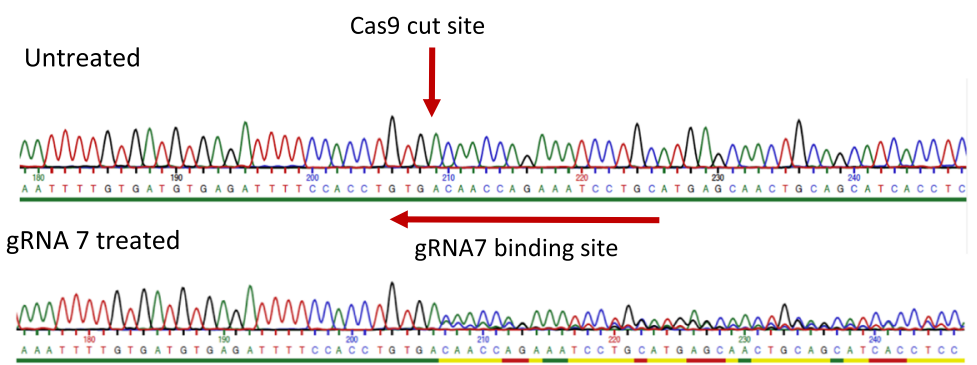

$\mathbf{E}$

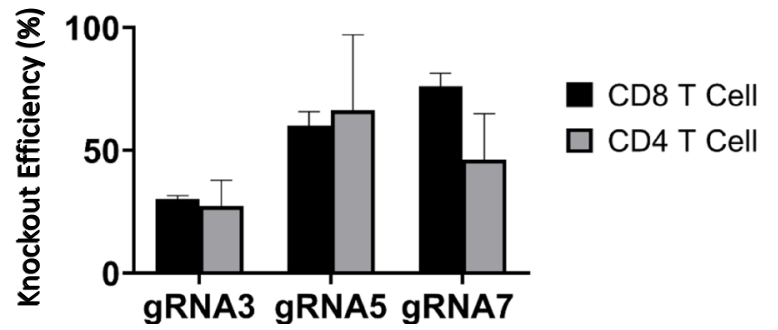

Fig. 3 (See legend on previous page.) 
A

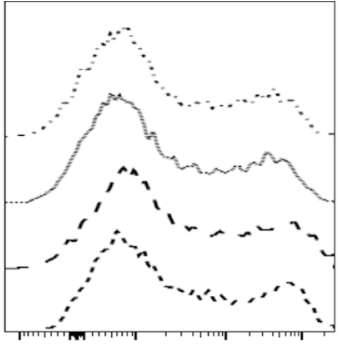

CAR MSLN- APC

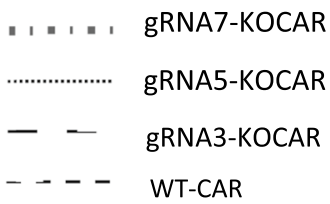

- - WT-CAR

\section{B}

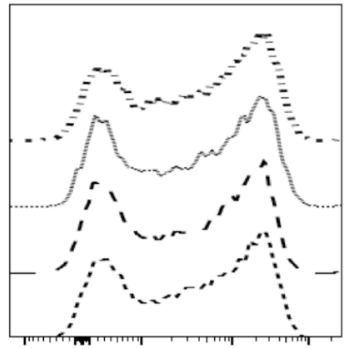

CAR CLDN6-AF647
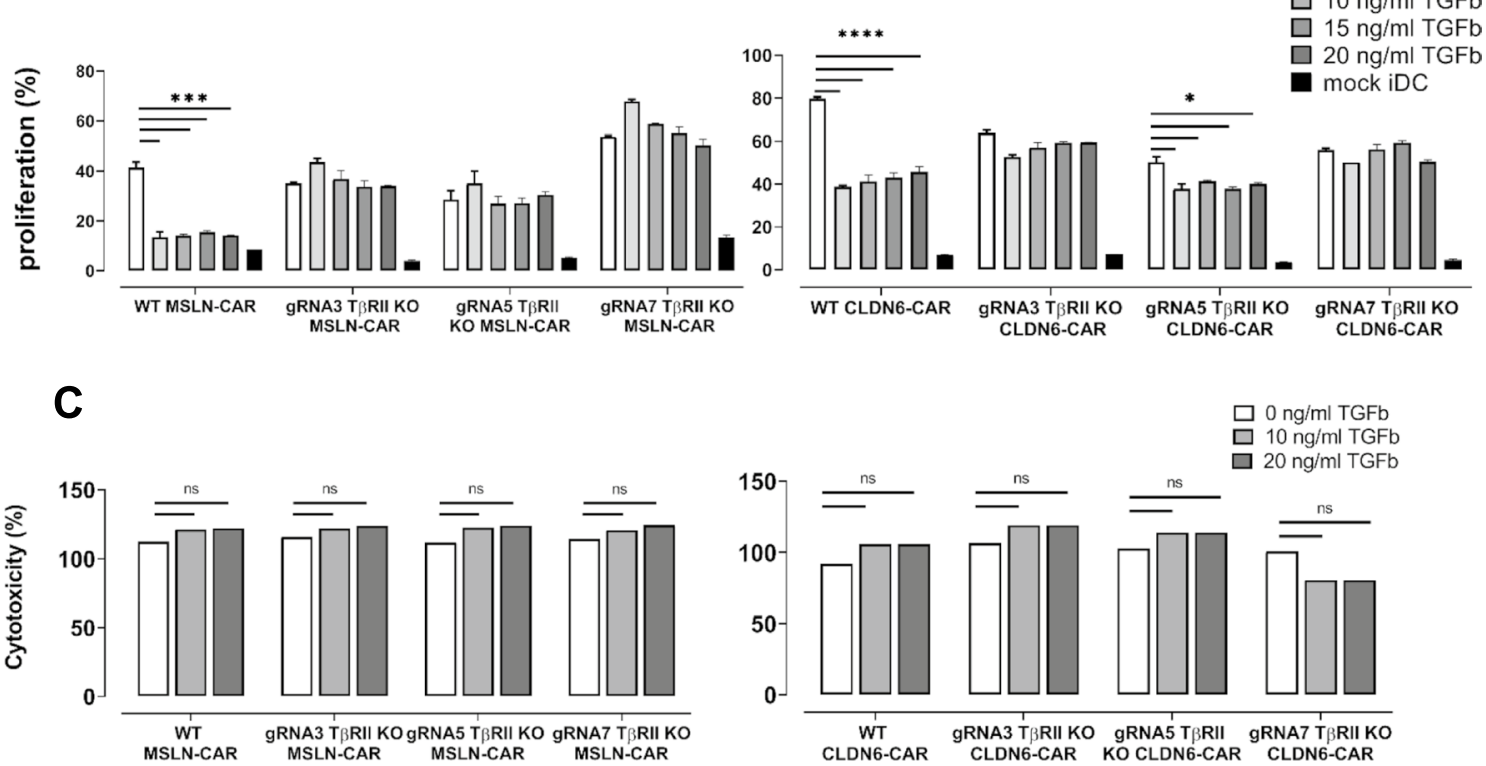

Fig. 4 Genomic TGF $\beta$ RII disruption in CART-cells specific for MSLN or CLDN6 enhances their in vitro effector functions. A Genomic editing of TGF $\beta R$ II in TGF $\beta R$ II KO CAR T-cells does not impact on CAR expression irrespective of the antigen specificity when compared to WT CART-cells. B TGF $\beta$ at any dose inhibits MSLN or CLDN6 4-1BBC CART-cell proliferation in the presence of antigen presenting iDCs as APCs. Of importance, proliferation of TGF $\beta R I I$ KO CAR T-cells remain unimpaired and stable even at a very high dose of exogenous TGF $\beta$. Proliferation in either WT or KO groups proved to be antigen specific. $\mathbf{C}$ In short-term classical cytotoxicity assays (luciferase based) against immunostimulatory iDCs, TGF $\beta$ does not impair cytotoxicity of WT CAR or TGF $\beta$ RII KO CART-cells. P values were determined by two-way Anova using multiple comparison test. *P $<0.05$; ${ }^{* *} \mathrm{P}<0.01 ;{ }^{* *} \mathrm{P}<0.001 ;{ }^{* * *} \mathrm{P}<0.0001$. In all experiments, mean $\pm \mathrm{SD}$ of three technical replicates are given and experiments, involving $\mathrm{T}$ cells, are repeated for at least three donors

CAR T-cells following electroporation in the absence of exogenous TGF $\beta$ to determine whether deletion of the TGFßRII gene has any impact on proliferation and/or survival of CAR T-cells. In most tests, we did not monitor any marked alterations in proliferation between WT and TGFßRII KO CAR T-cells and analysis among multiple donors did not result in a statistically elevated difference between WT and KO groups when the latter group was averaged over the 3 different gRNAs (white bars in Fig. 4B, and data not shown). Antigen independent expansion or cytokine secretion of KO CAR T-cells was absent leading to the conclusion that deletion of the TGF $\beta$ RII did not result in immortality (black bars in Figs. 4B and 5).

Again, TGF $\beta$ induced reduction of cell proliferation by more than a factor of 2 in WT CAR T-cells. Intriguingly, proliferation rates were restored in $\mathrm{CD} 8+$ and CD4+ TGFßRII KO CAR MSLN or CAR CLDN6 T-cells following stimulation with antigen presenting iDCs even in the presence of escalating doses of exogenous TGF $\beta$ (Fig. 4B). Of note, for TGF $\beta$ RII KO CAR MSLN T-cells we still observed a small but steady decline of dose 


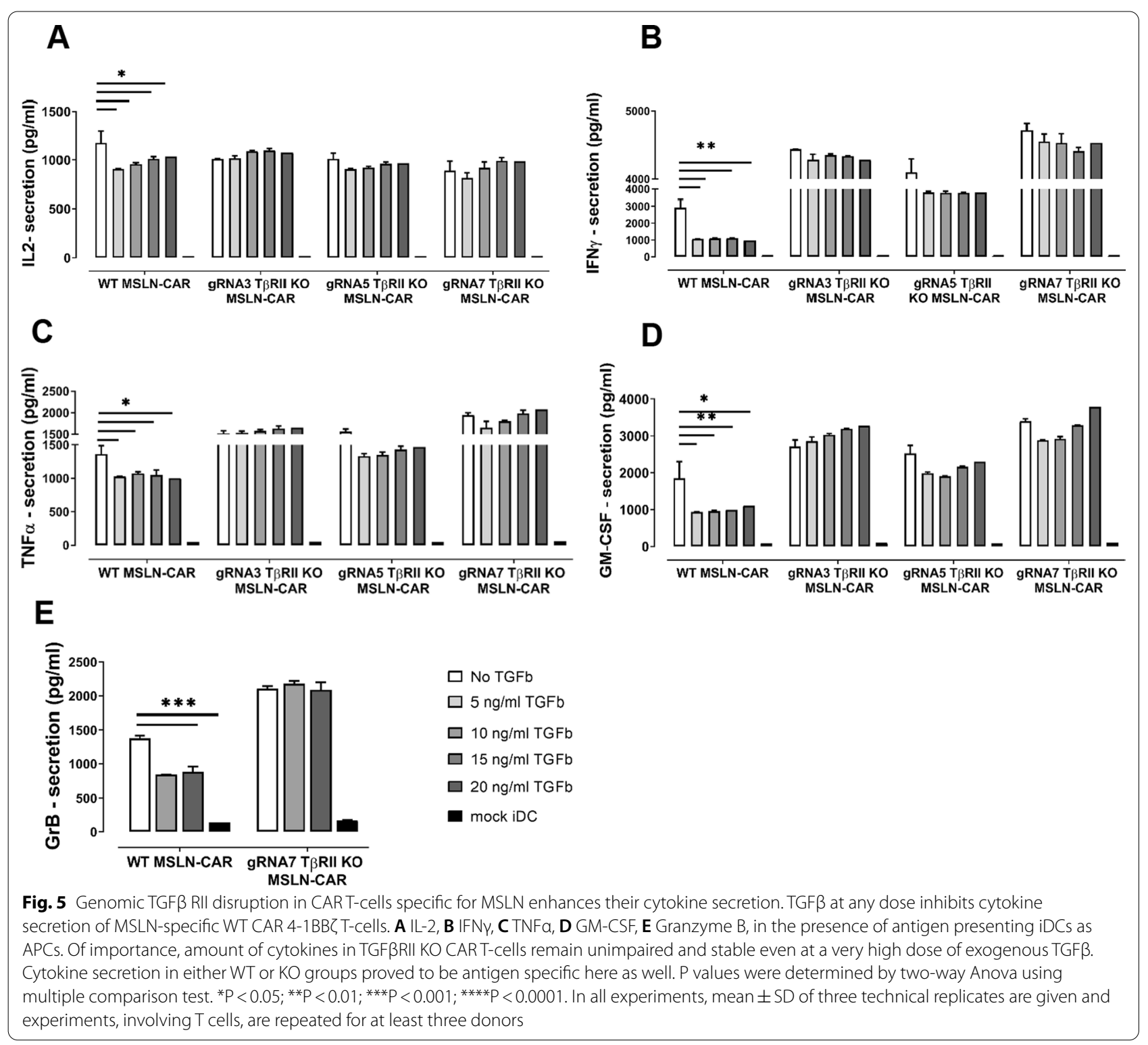

rate-dependent proliferation for 2 out of 3 gRNAs tested. Beside the dose effect, this may also result from a higher fraction of non-edited CAR T-cells in bulk CD8+T-cells used in the assay here, the former which is still susceptible to TGF $\beta$. It is important to note that rescue of proliferation is not complete: Despite the high recovery of proliferation in TGFbRII KO CAR-T groups, we observed proliferation efficacies for $\mathrm{KO}$ groups in the range of only up to approx. $60 \%$, that means at least $40 \%$ of them, either the WT fraction or even the KO fraction in bulk edited/non-edited KO groups, did still not proliferate. We also assessed the cytolytic potential of KO TGFBRII CAR T-cells specific for MSLN or CLDN6 against antigen loaded iDCs (Fig. 4C) in a bioluminescence cytolysis assay. However, in contrast to the proliferation and cytokine secretion results discussed before the killing efficiency of these KO CAR T-cells was not affected compared with the WT control. This has also been observed by others in a conventional cytotoxicity assay [23].

Nonetheless, when compared to WT CAR-T-cells, TGFBRII KO CAR-T-cells released equal amounts or a bit more of IL-2 (Fig. 5A, Additional file 3: S3A), IFN- $\gamma$ (Fig. 5B, Additional file 3: S3B), TNF $\alpha$ (Fig. 5C, Additional file 3: S3C), GM-CSF (Fig. 5D, Additional file 3: S3D)-cytokines, and GranB (Fig. 5E, Additional file 3: S3E) (tested just for one KO group/gRNA7) when they were cocultured with iDCs expressing the cognate antigen in the absence of exogenous TGF $\beta$. This cytokine 
release was dependent on CAR expression and nonelectroporated T-cells (mock) failed to release cytokines in the presence of antigen positive cells (data not shown) and there was no cytokine secretion in coculture of all CAR $\mathrm{T}$ cell groups with antigen negative iDCs (Fig. 5, black bars). Importantly, WT CAR-T-cells lost their ability to secrete cytokines in the presence of exogenous TGF $\beta$ to varying extents (Fig. 5, Additional file 3: Fig. S3) in the order IFN- $\gamma>$ GM-CSF $>$ GranB $>$ TNF- $\alpha>$ IL-2 in a TGF $\beta$ dose-independent manner. Contrary to that, TGFßRII KO CAR MSLN or CAR CLDN6 T-cells reset the immunusuppressive effect of TGF $\beta$ on cytokine secretion almost completely irrespective of the amount of suppression observed for WT CAR T-cells. Secondly, the antagonizing effect of TGF 3 RII KO CAR MSLN or CAR CLDN6 T-cells was on the whole independent of the dose of exogenous TGF $\beta$ added. We postulate that in general, a larger fraction of edited CAR T-cells being present in the bulk population dominate the fraction of non-edited CAR T-cells in the net outcome of function. This means to expect rather a gradual decrease of cytokine secretion in TGF $\beta$ RII KO CAR T-cells, which is true for most sample groups. However, a steady TGF $\beta$ dose rate-dependent increase of GM-CSF and TNF- $\alpha$ secretion became only evident for KO TGF $\beta$ RII CAR MSLN T-cells. This may be here due to the ratio of edited versus non-edited T-cells, the sensitivity of these cytokine secretion pathways towards TGF $\beta$, and the somewhat lower efficacy of CAR MSLN compared with CAR CLDN6.

In total, these results suggest that TGF $\beta$ RII disruption can antagonize in all three $\mathrm{KO}$ groups diverse longterm and short-term functional defects induced in WT MSLN or CLDN6 4-1BBל CAR T-cells treated with exogenous TGF $\beta$. However, our experiments did not reveal any effect of exogenous TGF $\beta$ in short term killing assays $(4 \mathrm{~h})$ against immunostimulatory target cells such as iDCs, neither for WT nor KO CAR T-cells.

\section{TGF $\beta$ receptor II disruption augments long term cytotoxicity}

Several reports showed an inhibitory effect of TGF $\beta$ on the cytotoxicity of T-cells and CAR T-cells cells [24-27]. However, we could not reproduce any suppression in short term cytotoxicity assays against iDCs. Hence, we addressed the question whether then on a long term exposure, TGF $\beta$ can hinder the killing function of the CAR T-cells taking into account in particular the chronic prevalence of a suppressive milieu in TME over time in patients. For this, we switched to stably CAR modified T-cells to circumvent transient expression of CARs based on IVT-RNA. Thus, we decided to use virally transduced T-cells and target cells (Fig. 6A). Transduced T-cells were then evaluated for CAR expression (Fig. 6B), viability and
TGFßRII KO efficiency. Real-time cytotoxicity was measured using the impedance based technique on an Xcelligence device using adherent CLDN6 + PA-1 Sc12 cell line as target and WT and KO TGF $\beta$ RII CAR CLDN6- T-cells as effectors. Cells were incubated at an E:T ratio of 5:1.

WT and KO CAR CLDN6 T-cells were not meaningfully different in their cytotoxic function in the absence of TGF $\beta$ (Fig. $6 \mathrm{C}$, red curve). However, in the presence of TGF $\beta$, the killing efficacy of WT CAR CLDN6 T-cells was significantly impaired over the entire time range (72 h, black curve) to a steady-state level. Remarkably, although all three KO CAR CLDN6 T-cells revealed decreased cytotoxicity to the same extent within the first five hours after coculture setup with target cells, their cytolysis potency recovered in the presence of TGF $\beta$ and aligned with the level of cytolysis monitored over time for the non-TGF $\beta$-treated controls (Fig. 6C/D) $(\%$ cytolysis was calculated based on the formula provided in Material and methods: Specific lysis was assured by subtracting cytolysis of mock $\mathrm{T}$ cells). The initial reduction could be attributed to an immediate suppressive effect of TGF $\beta$ captured here in real-time for bulk WT/ KO T-cells against immunodeficient tumor cells in contrast to the results shown for immunostimulatory iDCs (Fig. 4C). After this lag-phase TGF $\beta$ RII KO CAR T-cells became resistant to the TGF $\beta$ effect and caught up with non-TGF $\beta$ treated CAR T-cells in their cytolytic efficacy. Hence, we postulate that CAR T-cells can indeed be suppressed by TGF $\beta$ also in their cytotoxic function as resolved here in a real-time setting. Importantly, this can be reverted with TGFBRII KO CAR T-cells in the long run.

\section{Genomically edited TGF $\beta$ unresponsive CAR T-cells can escape control by induced regulatory T-cells.}

TGF $\beta$ not only commits naïve CD4 cells to differentiate into Tregs, but this cytokine also represents one of the principle mechanisms by which Tregs suppress their primary target cells, namely effector T-cells [28-30]. It has been shown in the past that $\mathrm{T}$-cells which do not respond to TGF $\beta$ are able to escape control by regulatory T-cells [31]. It is well known that Tregs are highly abundant in TME, especially in tumors with high level of TGF $\beta$ secretion, so we prompted us to verify whether TGF $\beta$ RII KO CAR T-cells were not only able to withstand TGF $\beta$ but also to resist the suppressive effect of Tregs (Fig. 7A). For such experiments, we were challenged to generate Tregs ex vivo from PBMCs in sufficient numbers which were referred to as induced regulatory T-cells (iTregs). The detailed protocol for generating iTregs has been described elsewhere [32]. In brief, CD4+ cells were activated with anti CD3, anti CD28 and IL2. The $\mathrm{CD} 4+$ cells which were treated this way represent 
A Schematic representation of long-term cytotoxicity assay work flow
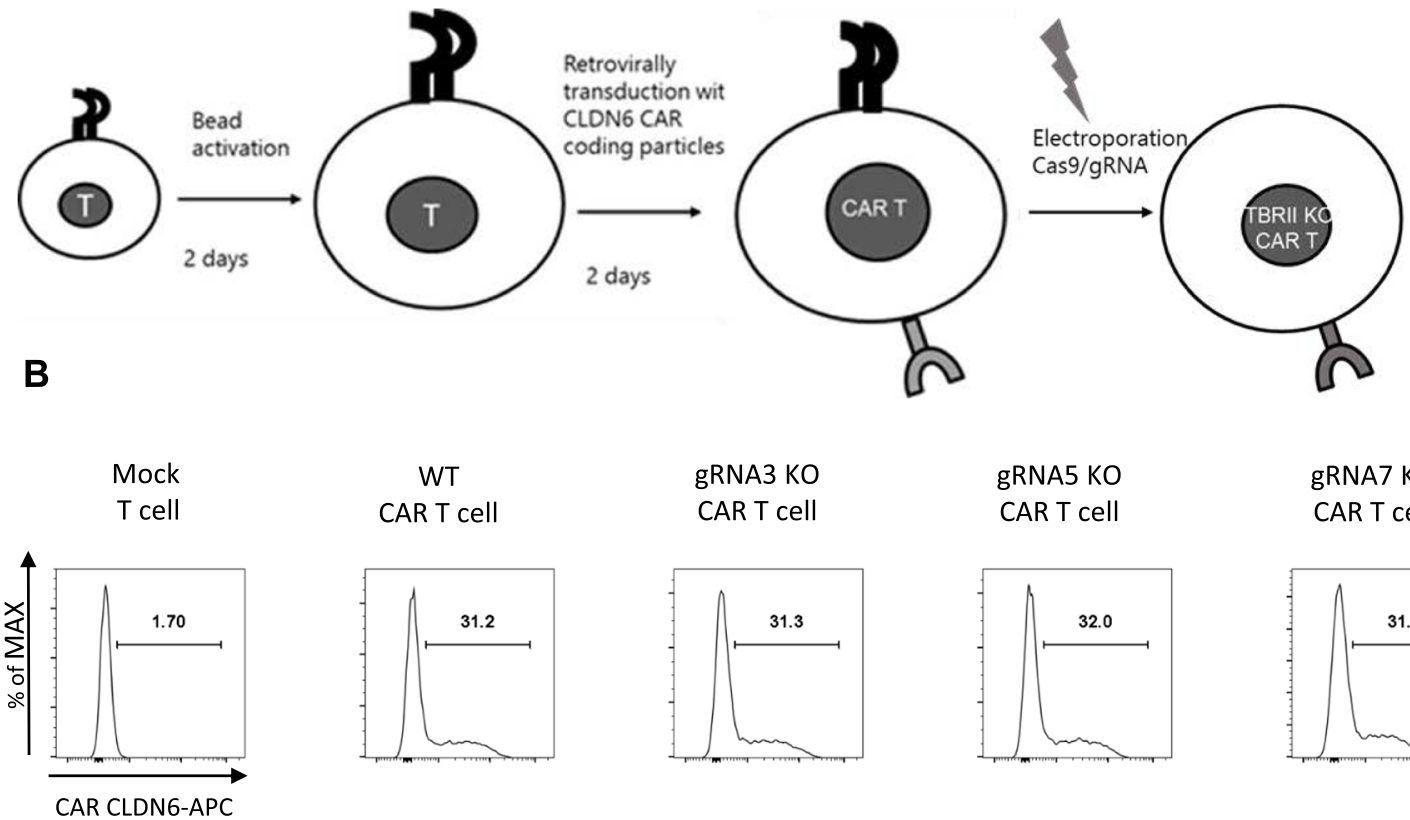

WT CAR T cell

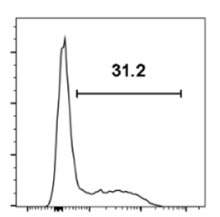

gRNA3 KO

CAR T cell

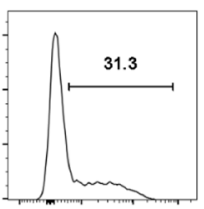

gRNA5 KO

CAR T cell

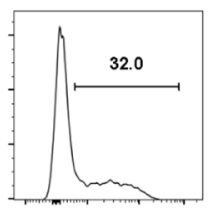

gRNA7 KO

CAR T cell
C

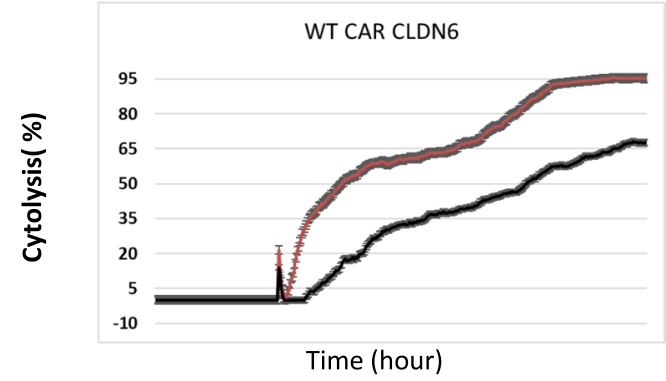

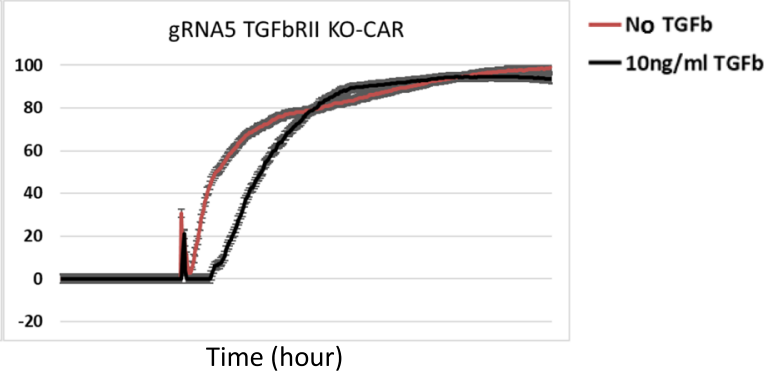

D
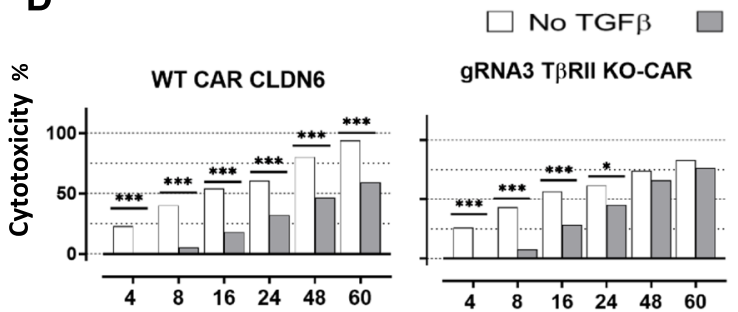

$10 \mathrm{ng} / \mathrm{ml} T \mathrm{TF} \beta$

gRNA5 TBRII KO-CAR

gRNA7 TRRII KO-CAR
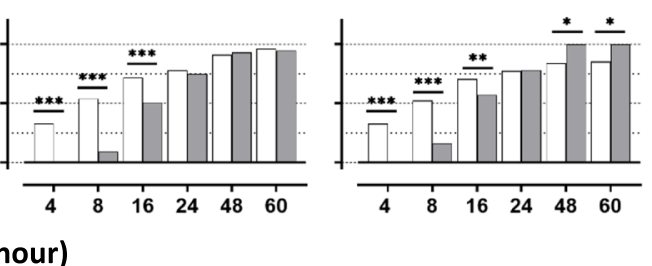

\section{Time (hour)}

Fig. 6 Genomic deletion of TGF $\beta$ receptor II restores long term cytotoxicity of TGF $\beta R \|$ KO CAR T-cells. A Schematic representation of long-term cytotoxicity assay work flow. Retroviral transduction of CD8+T-cells with CAR CLDN6 supernatants is followed by CRISPR/Cas9 treatment to disrupt TGF $\beta R \| l$ expression. B Equal CAR CLDN6 surface expression on retrovirally transduced WT and TGF $\beta R I I$ KO T-cells. C Impedance based cytotoxicity assay in the absence (red) and presence (black) of TGF $\beta$. The averaged cell indexes of triplicates were normalized to the time shortly before seeding effector CAR T-cells, and then recalculated to \%cytolysis according to the formula given in Material and methods. In the presence of TGF $\beta$, WT CAR T-cells were compromised in cytotoxicity towards CLDN6+ tumor c.l. PA-1 lower the entire incubation time ( $>3$ days), while cytotoxicity of TGF $\beta R \|$ KO CAR T-cells recovered after 20 h. D Cytotoxicity bar chart of WT and TGF $\beta R I I$ KO CART-cells in the absence (white bars) and presence (grey bars) of $10 \mathrm{ng} / \mathrm{ml}$ TGF $\beta$ at designated time points taken from B. The initial gain in cytotoxicity for non-TGF $\beta$ treated KO CART-cells in comparison to the TGF $\beta$-treated KO CART-cells levelled out over time $(24 \mathrm{~h})$ and led to comparable or even better cytolyses compared to WT CART-cells. P values were determined by two-way Anova using multiple comparison test. ${ }^{*} \mathrm{P}<0.05 ;{ }^{* * P}<0.01 ;{ }^{* * P}<0.001 ;{ }^{* * *} \mathrm{P}<0.0001$. In all experiments, mean $\pm S D$ of three technical replicates are given and experiments, involving $T$ cells, are repeated for at least three donors 


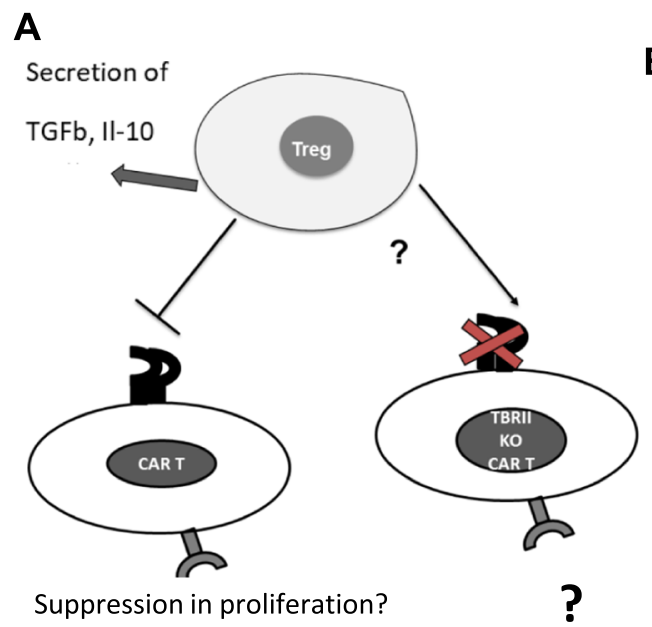

Reduction in IFNg secretion?
B Naïve T cells $\quad$ Activated T cells $\begin{gathered}\text { Activated T cells } \\ \text { TGFb+Rapa+ATRA }\end{gathered}$
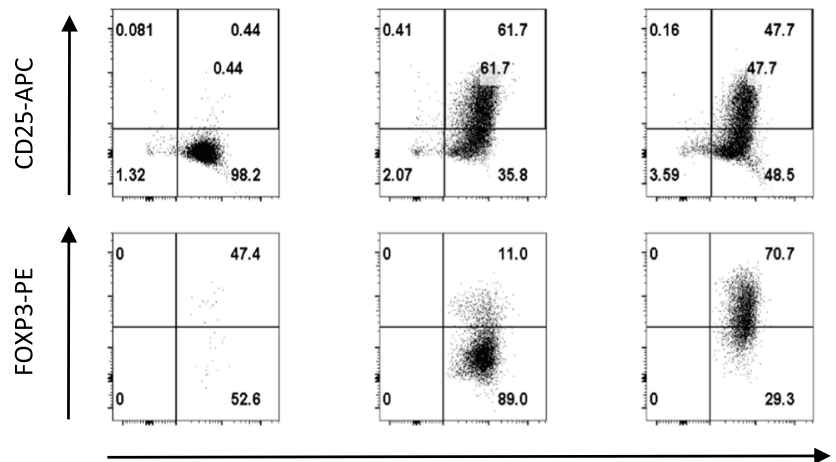

CD4-APC-Cy7
C

$\square$ Full proliferation $\square 12.5 \mathrm{ng} / \mathrm{ml}$ TGFb $\boldsymbol{\otimes}$ CD4:CART 2:1 mock iDC

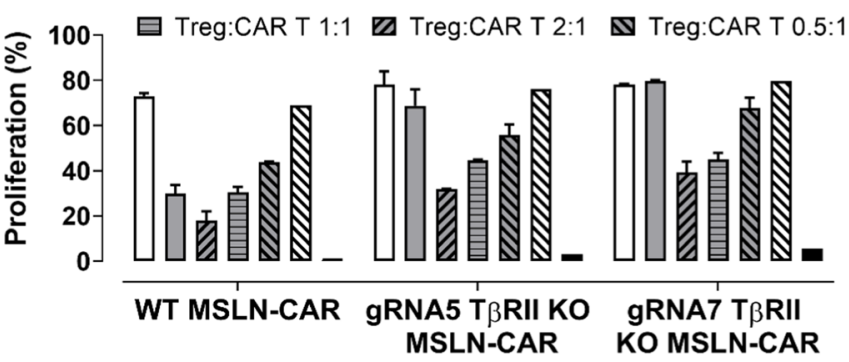

D

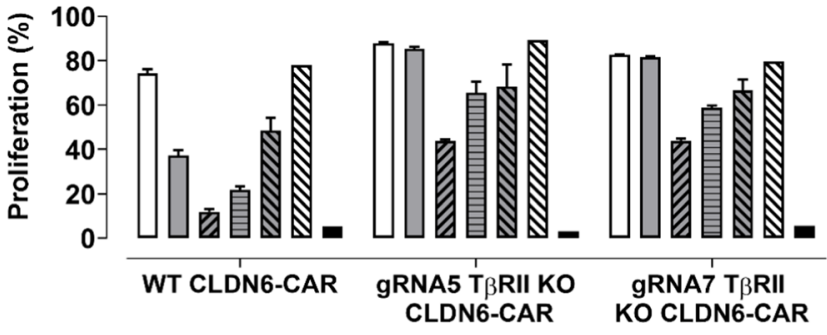

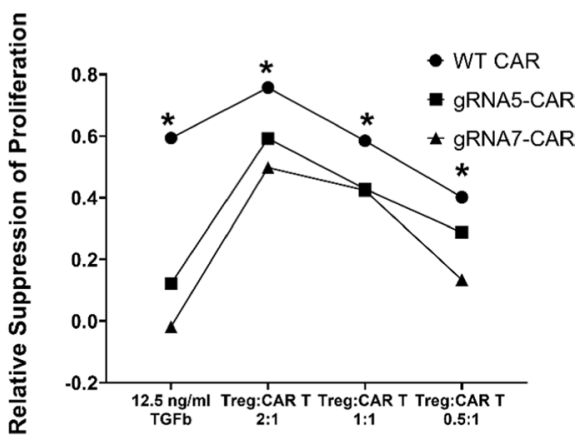

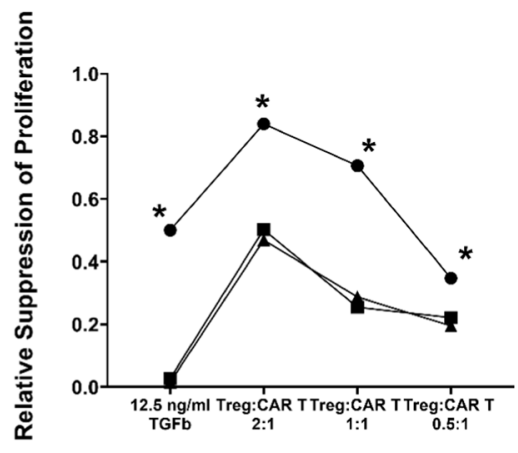

Fig. 7 Genomically edited TGF $\beta$ CAR T-cells can escape control by induced regulatory T-cells. A Schematic representation of the working hypothesis to assess the inability of iTregs to suppress TGF $\beta R I I$ KO CART-cells: Genomic disruption of TGF $\beta R I I$ expression leads to functional unresponsiveness towards TGF $\beta$ secreted by iTregs 'in situ'. This deactivates suppression of iTregs and hence, promotes better effector functions of responder T-cells such as antigen-dependent proliferation towards antigen electroporated iDCs. B Flow cytometry analysis of in vitro generated iTregs to confirm their phenotypic differentiation into CD4+T-cells with regulatory functions. CD25 were overexpressed in both, CD4+T-cells being solely activated by CD3 and CD28 and iTregs while the transcription factor FOXP3 was only overexpressed in the TGF $\beta / A l l$ trans retinoic acid /Rapamycine treated iTreg group. C/D Bar chart of normalized proliferation for WT and TGF $\beta R I I$ KO CAR T-cell groups, the latter genomically edited at the TGF $\beta R I I$ locus with 2 different gRNAs. CART-cell groups were either treated with exogenous TGF $\beta$ or cocultured with in vitro generated iTregs at iTreg:CART-ratios ranging from 2:1 down to 0.5:1. From this, iTregs can suppress WT CAR T-cell proliferation at any effector:responder-ratio in a dose-dependent manner. Bulk KO CAR T-cells are also prone to suppression by TGF $\beta$ secreted by iTregs, but are able to substantially resist, in particular at lower iTreg:CART-ratios (0.5:1 for CART MSLN; 0.5:1 and 1:1 for CART CLDN6) towards iDCs pulsed with MSLN (C) or CLDN6 (D). On the right, the relative changes in proliferation suppression are calculated from $\mathbf{C} / \mathbf{D}$ left. P values were determined by two-way Anova using multiple comparison test. ${ }^{*} \mathrm{P}<0.05 ;{ }^{* * P}<0.01 ;{ }^{* *} \mathrm{P}<0.001 ;{ }^{* * *} \mathrm{P}<0.0001$. In all experiments, mean $\pm \mathrm{SD}$ of three technical replicates are given and experiments, involving $T$ cells, are repeated for at least three donors 
activated CD4+T-cells as negative control for immunosuppression. For differentiation into iTregs, rapamycin, retinoic acid and TGF $\beta$ were subsequently added to the culture medium. T-cells were activated for up to 6 days, and then analyzed for FOXP3 and CD25 expression to confirm their iTreg phenotype (Fig. 7B). One day before setting up the coculture WT and TGF $\beta$ RII KO T-cells were electroporated with CAR MSLN (Fig. 7C) or CLDN6 (Fig. 7D) IVT-RNAs and iDCs were electroporated with the respective antigen encoding IVT-RNAs. Since we aimed at demonstrating cessation of the suppressive effect of induced regulatory effector T-cells in a proliferation assay, responder CD8+T-cells were stained with CFSE before seeding. For setting up the coculture, fixed numbers of iDCs and WT or KO CAR T-cells were coseeded and iTregs were added for different ratios to CAR T-cells (2:1, 1:1 and 0.5:1; Fig. 7C/D). The responder groups comprised beside the WT CAR T-cells as reference 2 different TGF $\beta$ RII KO CAR Tcell groups each treated with one of the CRISPR/Cas9 gRNAs 5 or 7 , respectively. As positive control we included the addition of exogenous TGF $\beta$ in the absence of iTregs, to confirm on the one hand that WT CAR T-cells are susceptible to suppression and on the other hand that TGFßRII KO CAR T-cells generated ex vivo are resistant to the anti-proliferative effect of exogenous TGF $\beta$ (Fig. 7C/D, second outmost left). Eventually, WT and KO CAR T-cells elicited comparable rates of proliferation in the absence of exogenous TGF $\beta$ (Fig. 7C, D outmost left). Activated CD4+ T-cells turned out to be not able to suppress WT and TGF $\beta$ RII KO CAR T-cells. Intriguingly, in vitro generated iTregs can inhibit proliferation of WT CAR T-cells even at the lowest iTreg to CAR T-cell ratio, ranging from excess 2:1 down to 0.5:1. Most importantly, although iTregs can also inhibit the TGFßRII KO CAR T-cells a little, the suppressive effect is less pronounced in a iTreg dose-dependent fashion compared to that in case of WT CAR T-cell. The remaining suppressive effect in 2 gRNA treated groups may at least in part be explained by the bulk T-cell populations used here, comprising unedited and hence TGF $\beta$-responsive WT CAR T-cells and TGFßRII KO CAR T-cells in each group. We should also keep in mind that Treg exert several other mechanisms to suppress $\mathrm{T}$ cells such as secretion of IL-10 and IL-35 [33] and hence the TGFßRII KO CAR $\mathrm{T}$ cells are not fully resistant to iTregs. This phenomena could be a layer of safety in using these kind of KO CAR T cells as they are not fully resistant to regulatory mechanisms by the immune system. The suppressive effect is most likely due to TGF $\beta$ produced endogenously by the induced regulatory T-cells leading to a paracrine effect because we solely targeted TGF $\beta$ RII via CRISPR/ Cas9 in responder T-cells. Since iTregs have not been equipped with CLDN6 or MSLN-specific CARs, iTreg/ iDC*Ag cell/cell contacts are highly unlikely to occur and to contribute to the suppressive effect towards responder T-cells observed here [34].

TGF $\beta R I I$ KO rescues CAR T-cell exhaustion induced by TGF $\beta$ Finally, we explored if TGF $\beta$ is also able to foster CAR T-cell exhaustion characterized by decreasing functional responsiveness, using a repetitive antigen stimulation assay, and whether the KO of TGFßRII on CAR T-cells are able to prevent this counter-regulatory effect. In a series of experiments, we took advantage of the impedance based cell killing assay: For this, the generation of stably modified CAR T-cells by means of retroviral transduction was a prerequisite in long term restimulation experiments. CAR T-cells were cocultured with the cell line OCVAR3 which expresses CLDN6 endogenously, at an E:T ratio of 5:1.

In the first (Fig. 8Ai) and second (data not shown) round of stimulation TGF $\beta$ revealed initial suppression within a few hours (Fig. 8Aii/Aiii) on cytotoxicity, but was not able to mount a long-lasting suppressive effect on the cytotoxicity of the CAR T-cells, neither on WT nor TGF $\beta$ RII KO CAR T-cells, the latter shown for gRNA 5 and 7, respectively. The reduction in cytotoxicity

(See figure on next page.)

Fig. 8 TGF $\beta R / l$ KO counteracts CART-cell exhaustion induced by TGF $\beta$. A OVCAR-3 cell line were seeded on an xcelligence plate and after $20 \mathrm{~h}$, retrovirally transduced WT or TGF $\beta$ RII KO CAR CLDN6 T-cells were added at an E:T ratio of 5:1 in the presence or absence of TGF $\beta$. After $48 \mathrm{~h}$, T-cells were collected, washed and counted, and seeded again on a new plate with freshly seeded adherent OVCAR-3 cell line almost growing in saturation phase $(20 \mathrm{~h})$. This procedure was repeated one more time to end up with 3 cycles of antigen-specific stimulation. i) A first round of coculture demonstrated that normalized cell indices for WT and TGF $\beta R I I$ KO CAR T-cells were barely affected by the presence of TGF $\beta$; ii) a first round of coculture did also not hamper cytotoxicity of any CART-cell group. iii) Max cytotoxicity is given here for a late time point (48 h of coculture) indicating no difference in cytotoxic efficacy. B A third round of coculture demonstrated a vast effect of TGF $\beta$ on cytotoxicity of WT CAR CLDN6 T-cells. i) Normalized cell indexes for third round of coculture of WT CAR T-cells or TGF $\beta R$ IIKO with OVCAR-3 cells indicate a significant difference in cytotoxicity when comparing these groups. ii) Bar chart of the calculated cytotoxicity demonstrating a long-lasting repression of WT CAR CLDN6 T-cells while the TGF $\beta R$ II KO CART-cells recovered from a short suppression phase and remained fully functional in the end (48 h). iii) Max cytotoxicity is given here for a late time point (48 $\mathrm{h}$ of coculture) indicating a substantial difference in cytotoxic efficacy. $\mathrm{P}$ values were determined by two-way Anova using multiple comparison test. ${ }^{* P}<0.05$; ${ }^{* *} \mathrm{P}<0.01$; ${ }^{* *} \mathrm{P}<0.001$; ${ }^{* * *} \mathrm{P}<0.0001$. In all experiments, mean $\pm \mathrm{SD}$ of three technical replicates are given and experiments, involving $T$ cells, are repeated for at least three donors. C After third round of coculture with OVCAR-3, the CAR T cells were collected, washed and stained for immune check point and exhaustion markers PD-1 and TIM 3. Bar chart representing the percentage of i: PD-1 and 2: TIM3 positive cells are shown 
A

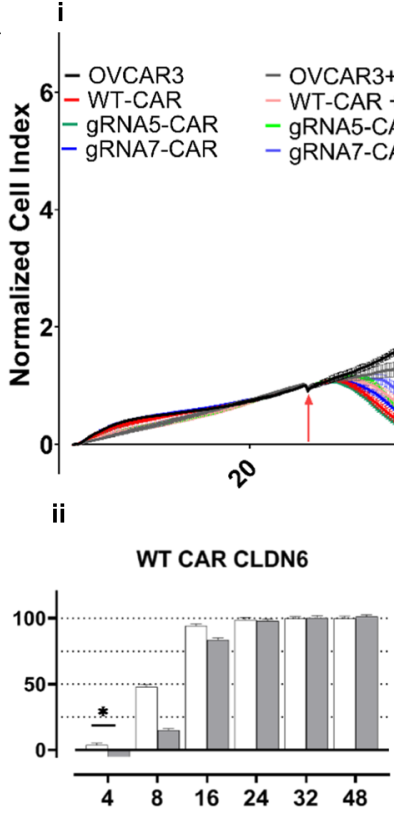

B i

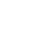

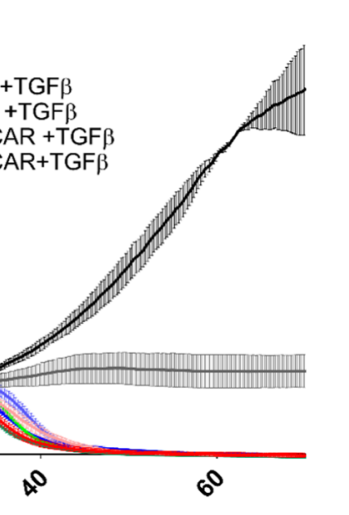

(n)

gRNA5-CARCLDN6

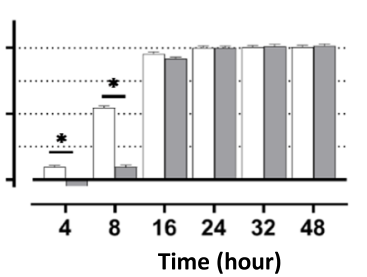

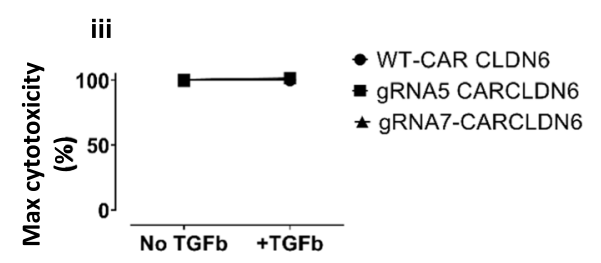

gRNA7-CARCLDN6

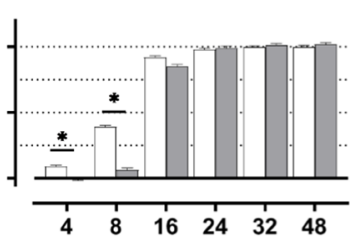

$\square$ No TGF $\beta$

$\square 10 \mathrm{ng} / \mathrm{ml} \mathrm{TGF} \beta$
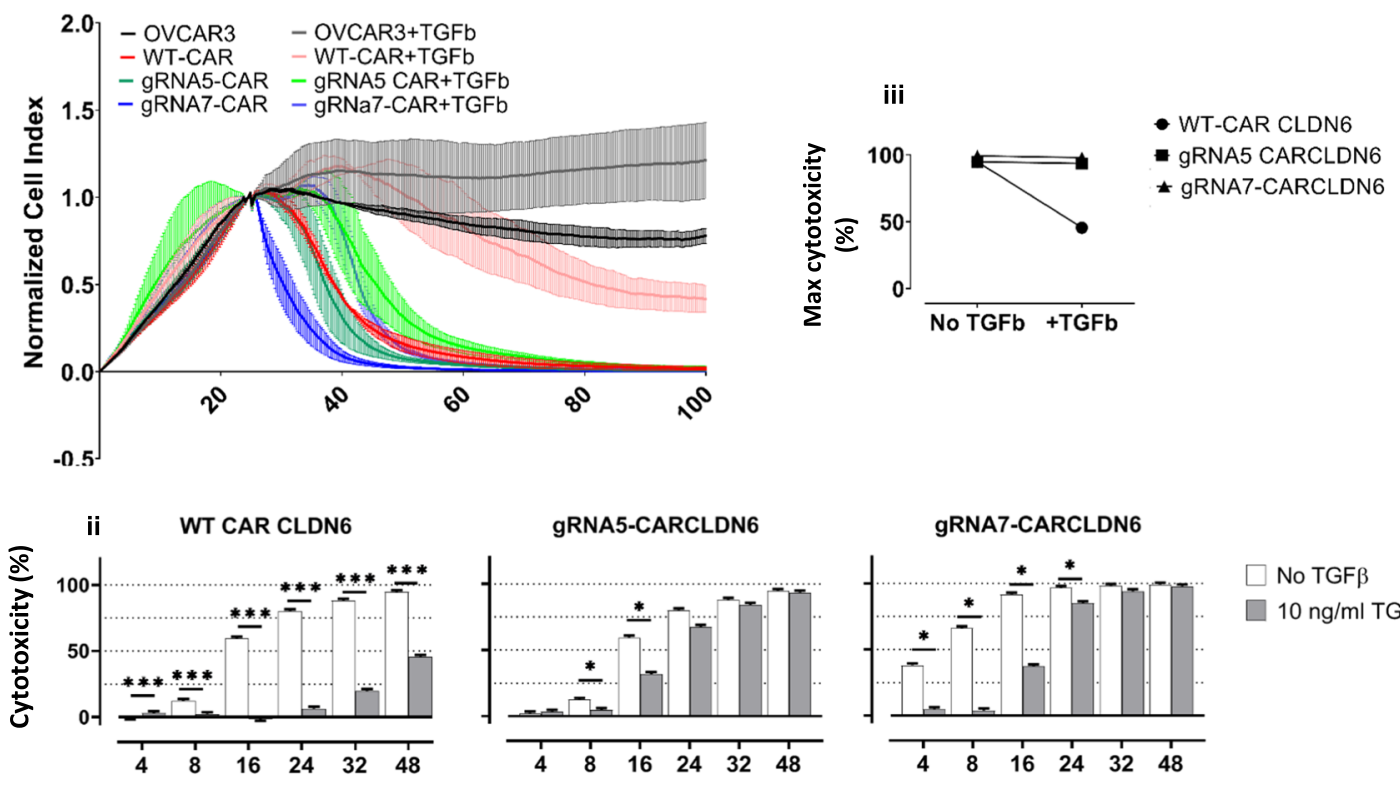

gRNA5-CARCLDN6

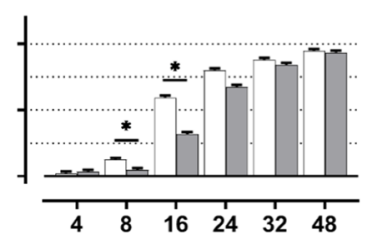

gRNA7-CARCLDN6

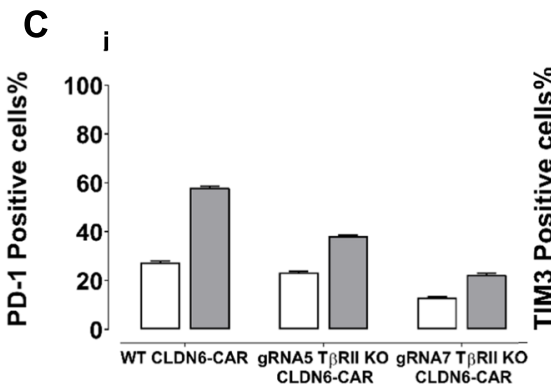

Time (hour)

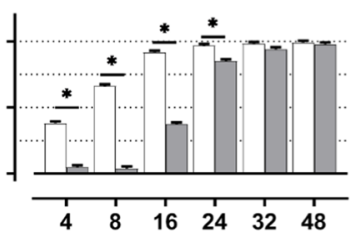

$\square$ No TGF $\beta$

$\square 10 \mathrm{ng} / \mathrm{ml}$ TGF $\beta$

ii

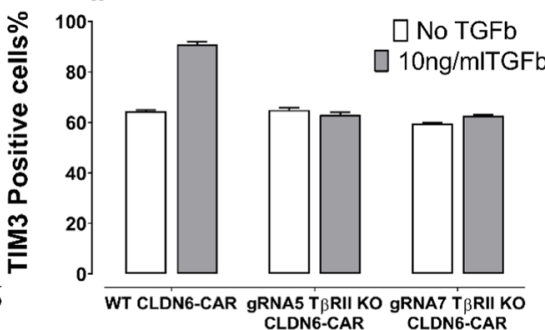

Fig. 8 (See legend on previous page.) 
in TGF $\beta$-treated samples was roughly the same for WT and TGFßRII KO CAR T-cells. Between 8 and $16 \mathrm{~h}$ of coculture lysis became complete for both groups. In the course of the third round of coculture (Fig. 8Bi), TGF $\beta$ untreated WT and $\mathrm{KO}$ T-cell groups sustained cytolytic function over time. On the other hand, WT CAR T-cells turned out to be for the first time vastly impaired in their cytotoxic function in the presence of TGF $\beta$ over the whole time frame (Fig. 8Bii): $48 \mathrm{~h}$ after setting up the assay lysis dropped down to less than $50 \%$ in comparison to the TGF $\beta$ untreated group.

In contrast, TGF $\beta$-treated TGF $\beta$ RII KO CAR T-cells recovered from a short suppression phase within $16 \mathrm{~h}$ and retained full lysis potency comparable to their related TGF $\beta$-untreated groups lasting till the end of experiment $(48 \mathrm{~h})$. We also checked the expression of two important exhaustion markers, PD-1 and TIM3 on the surface of different $\mathrm{T}$ cell groups after the third antigen stimulation. As it is depicted in Fig. 7C, all groups, upregulated the expression of this markers upon exposure to TGF $\beta$, however the upregulation in case of wild type CAR T cells was much more pronounced which is in line with our cytoxicity data.

We reasoned to see a suppressive effect of TGF $\beta$ on WT CAR T-cells only in round 3 of stimulation because the moderate endogenous expression rate of CLDN6 on ovarian cancer c.l. OVCAR-3 prevents premature exhaustion of WT CAR T-cells. This contrasts to the much higher expression seen on teratoma c.l. PA1, the latter which promotes early differentiation into senescent effector T-cells and hence, sensitivity towards TGF $\beta$ of WT CAR T-cells already after initial antigen-specific stimulation as outlined in Fig. 6.

To sum up the restimulation experiment, TGF $\beta$ exerts a less pronounced prohibitive effect on freshly activated CAR T-cells irrespective of being genomically silenced for TGF $\beta$ RII expression or not, but affects significantly cytotoxicity of repetitively antigen-experienced, and hence senescent CAR T-cells. Knock out of the TGF $\beta$ RII via CRISPR/Cas9 turns CAR T-cells, after a short lagphase, into effector T-cells unresponsive towards TGF $\beta$ in the long term and hence, emphasizes the benefit of ourapproach in generating more potent long-lived CAR T-cells in immunosuppressive TME.

\section{Discussion}

TGF $\beta$ is highly produced by many tumor types including ovarian malignancies $[35,36]$. Tumors can promote TGF $\beta$ production by tumor microenvironment resident cells such as fibroblasts $[37,38]$. TGF $\beta$ is a pleiotropic cytokine with diverse effects on cancer cells and the immune system. In premature phases of tumorigenesis, TGF $\beta$ acts as a tumor suppressor [39], whereas during progressed tumor immunoediting [40] cancer cells become resistant to the signaling and antitumor activity of this cytokine and in late stages, they gain genomic mutations which turn TGF $\beta$ to a tumor promoting agent $[7,41]$. On the other hand, TGF $\beta$ is a key regulator of immune homeostasis; in the context of $\mathrm{T}$ cells, TGF $\beta$ can inhibit proliferation, expression of cytolytic gene cytokines such as IFN- $\gamma$ and Granzyme B and Th1 differentiation and at the same time has a pivotal role in Treg generation $[5,10,24]$. There are also several reports on TGF $\beta$ suppressive effects on CAR T-cells functions, in terms of proliferation, cytotoxicity and cytokine secretion $[9,23,25,42]$.

Having in mind that TGF $\beta$ is likely to be one of the most important suppressor cytokines of CAR T-cell function, one may take into consideration different approaches to block its effects. Among the alternatives, localized blockade of TGF $\beta$ in tumors is not the best option, since tumor cells are not the only source of TGF $\beta$ in TME [5]. Although systemic blockade of TGF $\beta$ administering small-molecules or antibodies may act in a more efficient way it couldn't be ruled out to put the patient at risk of autoimmune disease. It should also be noted that TGF $\beta$ triggers apoptosis in pre-malignancies, so the systemic inhibition of TGF $\beta$ is not a reasonable option as it may confer tumorigenesis in other tissue regions [7].

Among the different possibilities, inhibiting the TGF $\beta$ signaling pathway in T-cells per se is an intriguing idea. Recently, a novel TGF $\beta$ specific CAR harboring a scFv against TGF $\beta$ has been reported which has the capacity of inhibiting endogenous TGF $\beta$ signaling and more interestingly converting TGF $\beta$ into a stimulus of T-cell growth [20]. Several other groups also attempt different approaches to tailor TGF $\beta$ pathway in the context of CAR T-cell therapy so as to improve CAR T-cell function in solid tumors.

Since TGF $\beta$ RII is the first cellular component in TGF $\beta$ signaling, it is reasonable to target this receptor in the first place to block immunosuppressive T-cell signaling. Kloss et al. reported on the overexpression of a dominant negative TGF $\beta$ RII which lacks the intracellular signaling domain in PSMA specific CAR T-cells leading to improved CAR T-cell function in vitro and in vivo [9]. However, this approach still allows for the expression of the wild type TGF $\beta$ RII and hence, will not abolish TGF $\beta$ mediated signaling in T-cells. Tang et al. reported that knocking out the endogenous TGF $\beta$ RII in CAR T-cells could reduce conversion to induced Tregs and prevent the exhaustion of CAR T-cells and led to better in vivo tumor elimination efficacy of CD28 second generation CARs specific for MSLN [25]. However, the authors did not assess, whether TGF $\beta$ produced by Tregs endogenously will affect other T-cells' function, as we could 
confirm in our work here. In a very recent study, Liu et al. [43] using a Cre-lox system, demonstrated that ablation of TGFBRII in CD4+ T-cells promotes tumor tissue healing and halts cancer progression, while in a back to back publication Li et al. [44] showed that blocking TGF $\beta$ signaling in CD4+ T-cells via Cre-lox system remodels the tumor microenvironment and restrains cancer progression. These approaches thoroughly demonstrate the usefulness to target TGF $\beta$ RII-signaling to foster T-cell effector functions in several models. However, they did not preclinically assess CRISPR/Cas9 to disrupt TGF $\beta$ RII as one of the most advanced tool in genomic editing, which already entered clinical phases in other studies [45]. Here, we hypothesized that genomically knocking out the TGF $\beta$ receptor via CRISPR/Cas9 in CAR T-cells will improve their functions in a solid tumor context as they will be able to resist the inhibitory effect of TGF $\beta$ in the immunosuppressive TME.

One of the most important obstacle is the choice of an optimal antigen [46-48]: Beside lack of tumor specific antigens on tumor cells, the majority of CAR T-cells targeting solid tumors are based on tumor associated antigens, which are highly expressed on tumor cells, but at the same time to some extent on normal tissue, which may lead to 'on target' but 'off tumor' toxicities. Here, we focused on two ovarian cancer associated antigens which were highly likely not or very rarely expressed on normal tissues. Reinhard et al. draw recently the conclusion that CLDN6 is an oncofetal cell-surface antigen with an ideal expression profile for CAR T-cell mediated immunotherapy (Fig. 1A) [13]. To also generalize our strategy we also focused on mesothelin (MSLN) specific CAR T-cells, which has been shown to represent a safe target in several clinical studies [49].

One should keep in mind that despite having CRISPR/ Cas9 $\mathrm{KO}$ efficacies in the range of $20-60 \%$ in CD4+ and CD8+T-cells depending on the gRNA used, we conducted our experiments with bulk CAR T-cells encompassing edited and unedited cells. Thus, the beneficial effects in TGF $\beta$ resistance should be even more pronounced for homogenously edited or purified T-cell populations. Nonetheless, we could clearly demonstrate that CAR T-cells benefit from knocking out TGFBRII in different aspects of anti-tumor function:

First, genomic inactivation of the TGF $\beta R I I$ signaling pathway does not affect expression of exogenously introduced CAR molecules irrespective of the expression system, which is an essential prerequisite to generate antigen-specific effector T-cells.

Secondly, TGF $\beta$ RII KO CAR T-cells were able to resist the anti-proliferative effect of TGF $\beta$ even at the highest dose of anti-inflammatory cytokine provided. This may not only positively affect the differentiation status and hence, viability and persistence of CAR T-cells but most importantly, the absolute number of therapeutic T-cells at the tumor site: Tumor eradication turns out to be the more efficient the more potent effector cells of a non-senescent phenotype such as central memory T-cells $\left(\mathrm{T}_{\mathrm{CM}}\right)$ mount an immune response against tumor cells [50]. Moreover, we demonstrated that responder TGFßRII KO CAR T-cells were also able to proliferate in the presence of TGF $\beta$ secreted 'in situ' by regulatory T-cells, which mimicks, at least in part, the immunosuppressive milieu in TME.

Thirdly, CAR T-cells are able to rescue their cytotoxic function in the presence of exogenous TGF $\beta$, even under conditions of repetitive antigen exposures: Here, we show that CD8+ TGF $\beta$ RII KO CAR T-cells retain their primary function in the presence of exogenously added excess TGF $\beta$. Antigen-experienced TGF $\beta$ RII KO CAR T-cells withstand suppression triggered by TGF $\beta$ and proved to retrieve full lysis upon successive cycles of restimulation despite their advanced differentiation in direction of a senescent phenotype. This feature is key to maintain a long-lived cytotoxic T-cell population to prevent the outgrowth of clonal tumor escape variants.

Fourthly, TGFßRII KO CAR T-cells were also able to preserve a set of cytokine secretions, whereas WT CAR T-cells were substantially hindered in secreting the proinflammatory cytokines such as TNF- $\alpha$ and IFN $\gamma$, the growth factors GM-CSF and IL2, and the cytotoxic mediator Granzyme B in the presence of exogenous TGF $\beta$ scrutinized here. In summary, our results support the notion that blocking the TGFBRII signaling pathway by means of its genomic deletion via CRISPR/Cas9 may represent a novel approach to antigen-specifically unleash anti-tumor CAR T-cell function in an otherwise suppressive tumor microenvironment.

\section{Conclusion}

It has been well established that TGF $\beta$ significantly suppresses the cytotoxic function of CD8+ T cells and also affects $\mathrm{CD} 4+\mathrm{T}$-cell differentiation and function by inducing their conversion into regulatory T-cells.

In the current study we prompted us to investigate the effect of a shutdown of the TGF $\beta$ signaling pathway exclusively in T-cells for two different second-generation BBC CARs specific for MSLN and CLDN6, respectively, taking advantage of the CRISPR/Cas9 genome editing tool. Our study clearly demonstrated that CAR T-cells benefit form knocking out TGF $\beta$ RII in different aspects of anti-tumor functionality: TGF $\beta$ RII KO CAR T-cells could resist the anti-proliferative effect of TGF $\beta$ even at the highest dose of cytokine applied, and they could preserve their cytotoxic function in the presence of exogenous TGF $\beta$ even in repetitive antigen exposure 
experiments. They could also retain their cytokine secretion profile, comprising TNF- $\alpha$, IFN $\gamma$, GM-CSF, IL2, and Granzyme B. We could also demonstrate that TGF $\beta$ RIIKO CAR T-cells can withstand the TGF $\beta$ mediated suppressive effect of iTregs 'in situ. In contrast, for WT CAR T-cells all effector functions assessed here were significantly impaired in the presence of TGF $\beta$. These observations may emphasize the perspective to apply the genomic disruption of the TGF $\beta$ RII-mediated signaling pathway as a means of fostering efficacy of CAR T-cell immunotherapy against immunosuppressive tumor entities in future clinical trials.

\section{Abbreviations}

CART-cells: Chimeric antigen receptor T-cells; c.l.: Cell line; TGF $\beta$ : Transforming growth factor $\beta$; TGF $\beta R I I$ KO CAR T-cells: TGF $\beta$ receptor II knocked out CAR T-cells; IVT: In vitro transcribed; MSLN: Mesothelin; CLDN6: Claudin 6.

\section{Supplementary Information}

The online version contains supplementary material available at https://doi. org/10.1186/s12967-021-03146-0.

Additional file 1: Figure S1. SK-OV-3 spheroid killing assay demonstrated that CAR MSLN T-cells react specifically and while recognize and kill HeLa cells at very low E:T ratio of 1:1, does not kill the SK-OV-3 cells at E:T ratio of $30: 1$.

Additional file 2: Figure S2. Histogram sequencing results for wild type and A: gRNA3 and B: gRNA5 treated groups, elicit a heterologous sequence 4 bases inside the gRNA target target sequence upstream of complementary 5'-NGG PAM-sequence, which is in line with indel formation.

Additional file 3: Figure S3. Genomic TGF $\beta$ RII disruption in CAR T-cells specific for CLDN6 enhances their cytokine secretion. TGF $\beta$ at any dose inhibits cytokine secretion of CLDN6-specific WT CAR 4-1BBZ T-cells. A: IL-2, B: IFNY, C:TNFa, D: GM-CSF, E: Granzyme B, in the presence of antigen presenting iDCs as APCs. Of importance, amount of cytokines in TGF $\beta R \|$ KO CAR T-cells remain unimpaired and stable even at a very high dose of exogenous TGF $\beta$. Cytokine secretion in either WT or KO groups proved to be antigen specific here as well. $P$ values were determined by two-way Anova using multiple comparison test. ${ }^{*} \mathrm{P}<0.05$; ${ }^{* * P}<0.01$; ${ }^{* * *} \mathrm{P}<0.001$; ${ }^{* * *} \mathrm{P}<0.0001$. In all experiments, mean \pm SD of three technical replicates are given and experiments, involving $T$ cells, are repeated for at least three donors.

\section{Acknowledgements}

We thank Ugur Sahin for his kind support during this project. In addition, we would like to thank the BioNTech cell and gene therapy (BCGT) team, in particular Petra Oehm, for technical advice and for giving us the opportunity to use the Xcelligence and Incucyte devices.

\section{Authors' contributions}

Study concept and design: $\mathrm{KA}, \mathrm{RHV}, \mathrm{SA}$ and $\mathrm{JH}$. Experiment performing: $\mathrm{KA}$ EM, LJ and HRM. Analysis and interpretation of data: Statistical analysis: KA, $\mathrm{RHV}, \mathrm{SA}, \mathrm{MD}, \mathrm{MB}$ and JH Drafting of the manuscript: KA and RHV. Critical revision and fnal approval of the manuscript: RHV, MD, MB and KA. Study supervision: $\mathrm{RHV}, \mathrm{MD}, \mathrm{SA}$ and $\mathrm{JH}$. All authors contributed to the article. All authors read and approved the final manuscript.

\section{Funding}

Open Access funding enabled and organized by Projekt DEAL. This study was financially supported by the institute of Translational Oncology (TRON) at the University Medical Center of the Johannes Gutenberg University Mainz, and grant no. 960404 of the Biotechnology Development Council of the Islamic Republic of Iran and grant no. 96011546 of the Iran National Science Foundation (INSF).

\section{Availability of data and materials}

The datasets used and analyzed during the current study are available from the corresponding author on reasonable request.

\section{Declarations}

Ethics approval and consent to participate

The studies does not involve any human participants and animals.

\section{Consent for publication}

All authors have approved the manuscript for submission.

\section{Author details}

${ }^{1}$ Department of Biotechnology, College of Science, University of Tehran, Tehran, Iran. ${ }^{2}$ TRON-Translational Oncology at the University Medical Center of Johannes Gutenberg University gGmbH, Mainz, Germany. ${ }^{3}$ Department of Immunology, School of Medicine, Tehran University of Medical Science, Tehran, Iran. ${ }^{4}$ Department of Research Center for Immunotherapy (FZI), University Medical Center (UMC) of the Johannes Gutenberg University, Mainz, Germany.

Received: 17 August 2021 Accepted: 16 November 2021 Published: 27 November 2021

\section{References}

1. Porter $\mathrm{DL}$, et al. Chimeric antigen receptor-modified T cells in chronic lymphoid leukemia. N Engl J Med. 2011;365:725-33.

2. Maude SL, et al. Tisagenlecleucel in children and young adults with B-cell lymphoblastic leukemia. N Engl J Med. 2018;378(5):439-48.

3. Neelapu SS, et al. Axicabtagene ciloleucel CAR T-cell therapy in refractory large B-cell lymphoma. N Engl J Med. 2017;377(26):2531-44.

4. Newick K, et al. CART cell therapy for solid tumors. Annu Rev Med. 2017:68:139-52.

5. Wrzesinski SH, Wan YY, Flavell RA. Transforming growth factor- $\beta$ and the immune response: implications for anticancer therapy. Clin Cancer Res. 2007;13(18):5262-70.

6. Massagué J. TGF $\beta$ in cancer. Cell. 2008;134(2):215-30.

7. Batlle $E$, Massagué J. Transforming growth factor- $\beta$ signaling in immunity and cancer. Immunity. 2019;50(4):924-40.

8. Derynck R, Budi EH. Specificity, versatility, and control of TGF- $\beta$ family signaling. Sci Signal. 2019. https://doi.org/10.1126/scisignal.aav5183.

9. Kloss CC, et al. Dominant-negative TGF- $\beta$ receptor enhances PSMAtargeted human CART cell proliferation and augments prostate cancer eradication. Mol Ther. 2018;26(7):1855-66.

10. Bollard CM, et al. Adapting a transforming growth factor $\beta$-related tumor protection strategy to enhance antitumor immunity. Blood J Am Soc Hematol. 2002;99(9):3179-87.

11. Narayan $\mathrm{V}$, et al. A phase I clinical trial of PSMA-directed/TGF $\beta$-insensitive CAR-T cells in metastatic castration-resistant prostate cancer. J Clin Oncol. 2019;37(7_suppl):TPS347.

12. Ushiku T, et al. Distinct expression pattern of claudin-6, a primitive phenotypic tight junction molecule, in germ cell tumours and visceral carcinomas. Histopathology. 2012;61(6):1043-56.

13. Reinhard K, et al. An RNA vaccine drives expansion and efficacy of claudin-CAR-T cells against solid tumors. Science. 2020;367(6476):446-53.

14. Bera TK, Pastan I. Mesothelin is not required for normal mouse development or reproduction. Mol Cell Biol. 2000;20(8):2902-6.

15. Morello A, Sadelain M, Adusumilli PS. Mesothelin-targeted CARs: driving T cells to solid tumors. Cancer Discov. 2016;6(2):133-46.

16. Holtkamp $\mathrm{S}$, et al. Modification of antigen-encoding RNA increases stability, translational efficacy, and T-cell stimulatory capacity of dendritic cells. Blood. 2006;108(13):4009-17. 
17. Zanoni M, et al. 3D tumor spheroid models for in vitro therapeutic screening: a systematic approach to enhance the biological relevance of data obtained. Sci Rep. 2016;6(1):1-11.

18. Gressner AM, et al. Roles of TGF-beta in hepatic fibrosis. Front Biosci Landmark. 2002;7(4):793-807.

19. Junker $U$, et al. Transforming growth factor beta 1 is significantly elevated in plasma of patients suffering from renal cell carcinoma. Cytokine. 1996;8(10):794-8.

20. Hou AJ, et al. TGF- $\beta$-responsive CAR-T cells promote anti-tumor immune function. Bioeng Transl Med. 2018;3(2):75-86.

21. Jinek $M$, et al. A programmable dual-RNA-guided DNA endonuclease in adaptive bacterial immunity. Science. 2012;337(6096):816-21.

22. Doench JG, et al. Optimized sgRNA design to maximize activity and minimize off-target effects of CRISPR-Cas9. Nat Biotechnol. 2016;34(2):184-91.

23. Golumba-Nagy V, et al. CD28- $\zeta$ CAR T cells resist TGF- $\beta$ repression through IL-2 signaling, which can be mimicked by an engineered IL-7 autocrine loop. Mol Therapy. 2018;26(9):2218-30.

24. Thomas DA, Massagué J. TGF- $\beta$ directly targets cytotoxic T cell functions during tumor evasion of immune surveillance. Cancer Cell. 2005;8(5):369-80.

25. Tang N, et al. TGF- $\beta$ inhibition via CRISPR promotes the long-term efficacy of CART cells against solid tumors. JCI Insight. 2020. https://doi.org/10. 1172/jci.insight.133977.

26. Stüber T, et al. Inhibition of TGF-ß-receptor signaling augments the antitumor function of ROR1-specific CAR T-cells against triple-negative breast cancer. J Immunother Cancer. 2020. https://doi.org/10.1136/ jitc-2020-000676.

27. Foster AE, et al. Antitumor activity of EBV-specific T lymphocytes transduced with a dominant negative TGF- $\beta$ receptor. J Immunother. 2008;31(5):500.

28. Nakamura K, Kitani A, Strober W. Cell contact-dependent immunosuppression by CD4+ CD25+ regulatory T cells is mediated by cell surfacebound transforming growth factor $\beta$. J Exp Med. 2001;194(5):629-44.

29. Nakamura K, et al. TGF- $\beta 1$ plays an important role in the mechanism of CD4+ CD25+ regulatory T cell activity in both humans and mice. J Immunol. 2004;172(2):834-42.

30. Chen M-L, et al. Regulatory T cells suppress tumor-specific CD8 T cell cytotoxicity through TGF- $\beta$ signals in vivo. Proc Natl Acad Sci. 2005;102(2):419-24.

31. Fahlén $L$, et al. T cells that cannot respond to TGF- $\beta$ escape control by CD4+ CD25+ regulatory T cells. J Exp Med. 2005;201(5):737-46.

32. Schmidt $A$, et al. Comparative analysis of protocols to induce human CD4+ Foxp3 + regulatory T cells by combinations of IL-2, TGF-beta, retinoic acid, rapamycin and butyrate. PLoS ONE. 2016;11(2): e0148474.

33. Schmidt A, Oberle N, Krammer P. Molecular mechanisms of Treg-mediated T cell suppression. Front Immunol. 2012. https://doi.org/10.3389/ fimmu.2012.00051.

34. Wright GP, et al. Adoptive therapy with redirected primary regulatory $T$ cells results in antigen-specific suppression of arthritis. Proc Natl Acad Sci. 2009;106(45):19078.

35. Thibault B, et al. Ovarian cancer microenvironment: implications for cancer dissemination and chemoresistance acquisition. Cancer Metastasis Rev. 2014;33(1):17-39.

36. Teicher BA. Malignant cells, directors of the malignant process: role of transforming growth factor-beta. Cancer Metastasis Rev. 2001;20(1):133-43.

37. Yu Y, et al. Cancer-associated fibroblasts induce epithelial-mesenchymal transition of breast cancer cells through paracrine TGF- $\beta$ signalling. $\mathrm{Br}$ J Cancer. 2014;110(3):724-32.

38. Dalal B, Keown P, Greenberg A. Immunocytochemical localization of secreted transforming growth factor-beta 1 to the advancing edges of primary tumors and to lymph node metastases of human mammary carcinoma. Am J Pathol. 1993;143(2):381.

39. Grady WM, et al. Mutational inactivation of transforming growth factor $\beta$ receptor type II in microsatellite stable colon cancers. Cancer Res. 1999;59(2):320-4.

40. Dunn GP, et al. Cancer immunoediting: from immunosurveillance to tumor escape. Nat Immunol. 2002;3(11):991-8.

41. Galliher AJ, Schiemann WP. $\beta 3$ integrin and Src facilitate transforming growth factor- $\beta$ mediated induction of epithelial-mesenchymal transition in mammary epithelial cells. Breast Cancer Res. 2006;8(4):1-16.
42. Chang $Z \mathrm{~L}$, et al. Rewiring T-cell responses to soluble factors with chimeric antigen receptors. Nat Chem Biol. 2018;14(3):317.

43. Liu M, et al. TGF- $\beta$ suppresses type 2 immunity to cancer. Nature. 2020;587(7832):115-20.

44. Li S, et al. Cancer immunotherapy via targeted TGF- $\beta$ signalling blockade in TH cells. Nature. 2020;587(7832):121-5.

45. Stadtmauer EA, et al. CRISPR-engineered T cells in patients with refractory cancer. Science. 2020;367(6481):7365.

46. Morgan RA, et al. Case report of a serious adverse event following the administration of T cells transduced with a chimeric antigen receptor recognizing ERBB2. Mol Therapy. 2010;18(4):843-51.

47. Richman SA, et al. High-affinity GD2-specific CART cells induce fatal encephalitis in a preclinical neuroblastoma model. Cancer Immunol Res. 2018;6(1):36-46.

48. Lamers $\mathrm{CH}$, et al. Treatment of metastatic renal cell carcinoma with CAIX CAR-engineered T cells: clinical evaluation and management of on-target toxicity. Mol Therapy. 2013;21(4):904-12.

49. Beatty $G L$, et al. Mesothelin-specific chimeric antigen receptor mRNAengineered $T$ cells induce antitumor activity in solid malignancies. Cancer Immunol Res. 2014:2(2):112-20.

50. Klebanoff CA, Gattinoni L, Restifo NP. Sorting through subsets: which T-cell populations mediate highly effective adoptive immunotherapy? J Immunother. 2012;35(9):651-60.

\section{Publisher's Note}

Springer Nature remains neutral with regard to jurisdictional claims in published maps and institutional affiliations.

Ready to submit your research? Choose BMC and benefit from

- fast, convenient online submission

- thorough peer review by experienced researchers in your field

- rapid publication on acceptance

- support for research data, including large and complex data types

- gold Open Access which fosters wider collaboration and increased citations

- maximum visibility for your research: over $100 \mathrm{M}$ website views per year

At BMC, research is always in progress.

Learn more biomedcentral.com/submissions 